\title{
ANDREAS VESALIUS ON THE LARYNX AND HYOID BONE: AN ANNOTATED TRANSLATION FROM THE 1543 AND 1555 EDITIONS OF DE HUMANI CORPORIS FABRICA
}

\author{
by
}

D. H. GARRISON and M. H. HAST *

\section{TRANSLATORS' NOTE}

Vesalius' training in anatomy was firmly rooted in the Galenic school of medicine, and it was Galen who, like one of the present translators, had a particular interest in the larynx and its surrounding anatomy. ${ }^{1}$ Although he was not completely free of Galen's reliance on animal models, ${ }^{2}$ Vesalius' account of the structure of the larynx is substantially accurate, and can be verified with reference to the standard anatomy books in use today. While his understanding of detail falls far short of what is now known about the anatomy and physiology of the chief organ of voice ${ }^{3}$ (his description of muscle actions is Galenic), Vesalius' achievement is readily visible both in what he wrote and what he directed his illustrators to engrave on the wood blocks - destroyed during World War II-which helped make the Fabrica a landmark of Renaissance printing.

It is astonishing that a Renaissance text as important as the Fabrica remains untranslated into a readily accessible modern language. To be sure, its companion volume, the Epitome, a standard anatomical textbook for medical students, was ably

* Dr D. H. Garrison, Department of Classics, Northwestern University, 1859 Sheridan Road, Evanston, Illinois 60208-2200, USA; Professor M. H. Hast, The Medical School, Northwestern University, Chicago, Illinois 60611, USA.

\footnotetext{
${ }^{1}$ See, for example, De usu partium, Books 7 and 16, (M. T. May, Galen on the usefulness of the parts of the body, Ithaca, Cornell University Press, 1968), and De anatomicis administrationibus, Books 11 and 14 (W. L. H. Duckworth, Galen on anatomical procedures, Cambridge University Press, 1962).

2 Vesalius employed both canine and bovine tissue in his anatomical demonstrations; see Ruben Eriksson, Andreas Vesalius' first public anatomy at Bologna, 1540. An eyewitness report, Uppsala and Stockholm, Almqvist \& Wiksells Boktryckeri, 1959.

${ }^{3}$ Chief among the findings about the larynx since Vesalius are (1) recognition and description of "aryepiglottic folds" [plica aryepiglottica] with muscle fibres from $m$. arytenoideus obliquus, named as pars aryepiglottica, which close the aryepiglottic sphincter like a purse-string, and muscle fibres of $m$. thyroarytenoideus, the pars thyroepiglottica which opens the aryepiglottic folds; the posterior margin of these folds contains the cartilago cuneiformis, first described by H. A. Wrisberg (1739-1808), Professor of Anatomy at Göttingen; (2) recognition and description of a third set of folds, plica vestibularis, with a rima vestibuli; (3) recognition and description of the ventriculus laryngis between the plica vocalis and the plica vestibularis; this "sinus of Morgagni" was first described by G. B. Morgagni (1682-1771), Professor of Anatomy at Padua; (4) recognition of a median bundle of muscle fibres of the thyroarytenoid muscle, named $m$. vocalis; (5) that the action of the lateral cricoarytenoid muscle is to adduct the membraneous portion of the rima glottidis, the pars intermembranacea; (6) that the cricothyroid muscle is innervated by
} 


\section{H. Garrison and M. H. Hast}

translated by L. R. Lind in $1949 .{ }^{4}$ Since Latin was the lingua franca of the medical profession from Roman times until the present century, it could once be assumed that medical scientists would be able to read whatever portions of the Fabrica they wished in the original language. This has long since ceased to be true, and a translation into a widely read modern language would be valuable for historians of medicine, as well as for anatomical scholars.

The Fabrica's roughly 350,000 words of Latin text present a formidable task to the translator. The Latin itself, while written according to the best humanist standards of neoclassical prose-indeed, because it was so written-is more stylish than transparent. The canon of classical Latin style was set in the first century BC by Cicero, and brought into medical writing by Celsus, the Cicero medicorum, in the first century AD. The resultant periodic style is distinguished by the leapfrogging of logical word order known to classical scholars as hyperbaton; words that naturally go together must be mentally re-united, and the predication of lengthy subordinate clauses determined and held in reserve until the main predication of a sentence arrives, like a triumphant proconsul, at the end of its verbal cavalcade. It is an elaborately artificial language, constructed and employed in times when a baroque impressiveness was more valued than rapidity or perspicuity. Besides its opaque word order, Latin in this tradition has a tendency to insert connective particles such as etenim, vero, ceterum, and etiam in the beginnings of sentences, leaving it to the reader to decide whether they are functional or simply ornamental. Vesalius' re-introduction of classical Latin to medical writing was a mixed blessing; it placed him on the one hand in the mainstream of humanist values, while on the other outside the easy reach of the average Latinist in his own time as well as ours. ${ }^{5}$ For the translator, such writing presents the difficult choice of paraphrasing Vesalius' Latin into fluent, readable English or translating more closely into clear but slightly awkward sentences. If we have erred, it has been on the side of the literal at the expense of the literate, in the hope of preserving some of the original character.

This translation is based on the first edition of the Fabrica, published in 1543. The second edition, published by Oporinus in 1555, contains many changes, more of them stylistic than substantive. ${ }^{6}$ Where Vesalius added, deleted, or rewrote more than a little, we have noted the change in footnotes rather than breaking into the text with insertions.

the nervus laryngealis superior, ramus externus, a branch of the vagus nerve, and not a branch of the hypoglossal nerve (called the "seventh nerve") as described by Vesalius. For a more complete description of the modern anatomy of the larynx, with illustrations, the reader should consult Gray's anatomy, 37th ed. edited by P. L. Williams, R. Warwick, M. Dyson, and L. H. Bannister, London, Churchill Livingstone, 1989.

${ }^{4}$ L. R. Lind, The epitome of Andreas Vesalius, New York, Macmillan, 1949. A two-volume Russian edition of the entire Fabrica, translated by V. N. Ternovski and S. P. Shestakov (Moscow, Akademia Nauk, 1950-54), is listed in Harvey Cushing's Bio-bibliography of Andreas Vesalius, 2nd ed., Hamden, Ct., Archon Books, 1962, p. 229.

${ }^{5}$ For an appreciation of Vesalius' humanist learning and neoclassical style, see Ludwig Edelstein, 'Andreas Vesalius; Humanist', in Bull. Hist. Med. 1943, 14, 547-61, reprinted in Ancient medicine, edited by O. and C. L. Temkin, Baltimore, Johns Hopkins Press, 1967, pp. 441-54.

${ }^{6}$ Vesalius' stylistic changes in the second edition are discussed by M. Roth, Andreas Vesalius Bruxellensis, Berlin, Reimer, 1892, p. 232, and C. D. O'Malley in Andreas Vesalius of Brussels, Berkeley, University of California Press, 1965, 272-82. 


\section{Andreas Vesalius on the larynx}

We have, however, interfered with the flow of the translation by admitting some intrusions that we felt would assist anyone wishing to follow Vesalius' account closely. First, we have inserted in brackets the modern anatomical name of each part mentioned by Vesalius, using as our guide the current edition of Nomina anatomica, ${ }^{7}$ the last vestige of Latinity in the modern science of anatomy. This identification compelled us to make the best possible sense of Vesalius' account, and the resultant signposts will be useful to any reader trying to reconstruct what Vesalius saw when he dissected the larynx. Other signposts have been brought in selectively; some of the references to text figures placed in the gutters of the original are included parenthetically. Instead of paragraphing, Oporinus placed topic headings in the outside margins; we have turned the most useful of these into sub-headings in the text, following modern typographical convention.

Finally, we avoided the temptation to turn our translation into an up-to-date text for modern students of basic anatomy. We do not wag our professorial finger to correct our author when we believe he is wrong, and we do not explain where we believe he has been incomplete. Our footnotes give background information on persons mentioned, Greek terms employed, and other matters that we think will be of interest to the reader.

For this translation of De humani corporis fabrica libri septem, we used a facsimile of the 1543 edition published by Culture et Civilisation, Brussels, 1964, copy number 1724. We wish to express our gratitude to Cecile E. Kramer, recently retired Librarian of the Galter Health Science Library of Northwestern University, for providing access to the $\mathbf{1 5 5 5}$ edition of Vesalius' Fabrica. For corrections and timely suggestions for the improvement of our translation, we are grateful to Dr Vivian Nutton and the anonymous referees of Medical History.

\section{BOOK I \\ CHAPTER 13}

\section{ON THE BONE WHICH LOOKS LIKE THE GREEK UPSILON}

KEY TO ILLUSTRATIONS AND LETTERS (see Plate A)

The first illustration of the present chapter represents the anterior face of the bone [corpus ossis hyoidei] ${ }^{8}$ resembling the letter $v$ [Greek upsilon], together with its lesser or more elevated sides [cornua minora] and the ossicles which are connected by them to the processes of the temporal bones, shaped in the fashion of a stylus [processus styloideus].

The second illustration shows the posterior region of the bone resembling a $v$, along with the more elevated ribs [cornua]: but for the moment we have not drawn those

\footnotetext{
${ }^{7}$ Nomina anatomica, 6th ed., International Anatomical Nomenclature Committee, Edinburgh, Churchill Livingstone, 1989.

${ }^{8}$ Italicized names in brackets are the current anatomical nomenclature, op. cit., note 7 above.
} 


\section{H. Garrison and M. H. Hast}

ossicles which extend to the processes that resemble a stylus and are drawn in the former illustration.

$\mathrm{ABC}_{1}{ }^{9}$ Larger and middle ossicle [corpus] of the hyoid bone, visible in its anterior seat. $A$ and $B$ indicate the protuberant region of this seat. In between these characters appears the particular tubercle of this region, marked*. C indicates the transversely elongated depression discernible in the superior seat of this middle bone.

$\mathrm{D}_{2} \quad$ Posterior seat of the larger ossicle [corpus], depressed and concave.

$\mathrm{EF}_{1,2}$ Lower sides [cornua majora] of the hyoid bone, which with the middle ossicle represent a figure like a $u$.

$\mathrm{G}_{1,2}$ Connections of the lower side [cornu majus] with the broader and larger ossicle of the hyoid bone.

$\mathrm{H}_{1,2}$ Apex of the lower side, which is attached to the process [cornu superius] of the laryngeal cartilage that resembles a shield.

$\mathrm{IK}_{1,2}$ Upper sides [cornua minora] of the hyoid bone, considerably thinner (and smoother) than the lower ones.

$\mathrm{LMN}_{1}$ Three ossicles, ${ }^{10}$ joined in the greatest degree to the upper sides [cornua minora]. Besides the fifth plate of the muscles at the letter $\mathrm{L}$, several earlier illustrations of Book Two, Chapter Twelve ${ }^{11}$ at A, B, C, and D further represent the hyoid bone.

\section{LOCATION AND NAMES OF THE HYOID BONE}

The bone included in the most prominent part of the larynx, but built up of various and numerous ossicles, is represented by a name implying unity; some call it hypsiloeidès from the shape of the letter $v$, others more succinctly hyoeidès: those without experience in dissection, misled by this term, have translated it in Galen as "the bone resembling a pig". 12 This bone is named elsewhere lambdoeides ["lambdashaped"] from the image of $\Lambda$; interpreters deceived by this name have become accustomed to translate it as the lambda-like suture of the head. But I for my part have recently removed errors of this sort from both Italian and German translations of Galen into Latin. Herophilus ${ }^{13}$ is also said to have called this bone parastates ["companion"], perhaps because it is located next to the tongue, or the larynx, or the jaws, just as in the organs serving generation he calls certain items "the varicose companion" [i.e. spermatic duct] and "the glandular companion". ${ }^{14}$ Moreover, there

\footnotetext{
${ }^{9}$ Subscript numbers refer to the first and second figures see p. 7 below.

${ }^{10}$ Ossified portions (?) (infrequent) of ligamentum stylohyoideum; more likely, this figure was drawn from a specimen of the canine hyoid bone and apparatus in which the cornu minus is connected to pars tympanica, vagina processus styloidei, by a series of ossicles unlike the ligamentum stylohyoideum of the human.

${ }_{11}$ Apparently a misprint: these illustrations appear in Chapter 21.

12 Because in Greek hys or sus means "pig".

${ }^{13}$ Herophilus was a medical writer from Chalcedon (4-3 century BC) frequently cited by Galen. The word $\pi \propto \rho \alpha \sigma \tau \dot{\alpha} \tau \eta \varsigma$ generally means "comrade", and is applied to the spermatic ducts as well as the hyoid bone. See May, op. cit., note 1 above, p. 26.

${ }^{14}$ For which see Galen, De usu partium 4.190.3ff., May, p. 644. References to the Greek text of De usu partium will be as given in the Thesaurus Linguae Graecae and the TLG Canon of Greek authors and works, 3rd ed., New York, Oxford University Press, 1990, followed by a page reference to M. T. May’s translation, op. cit., note 1 above.
} 
Andreas Vesalius on the larynx

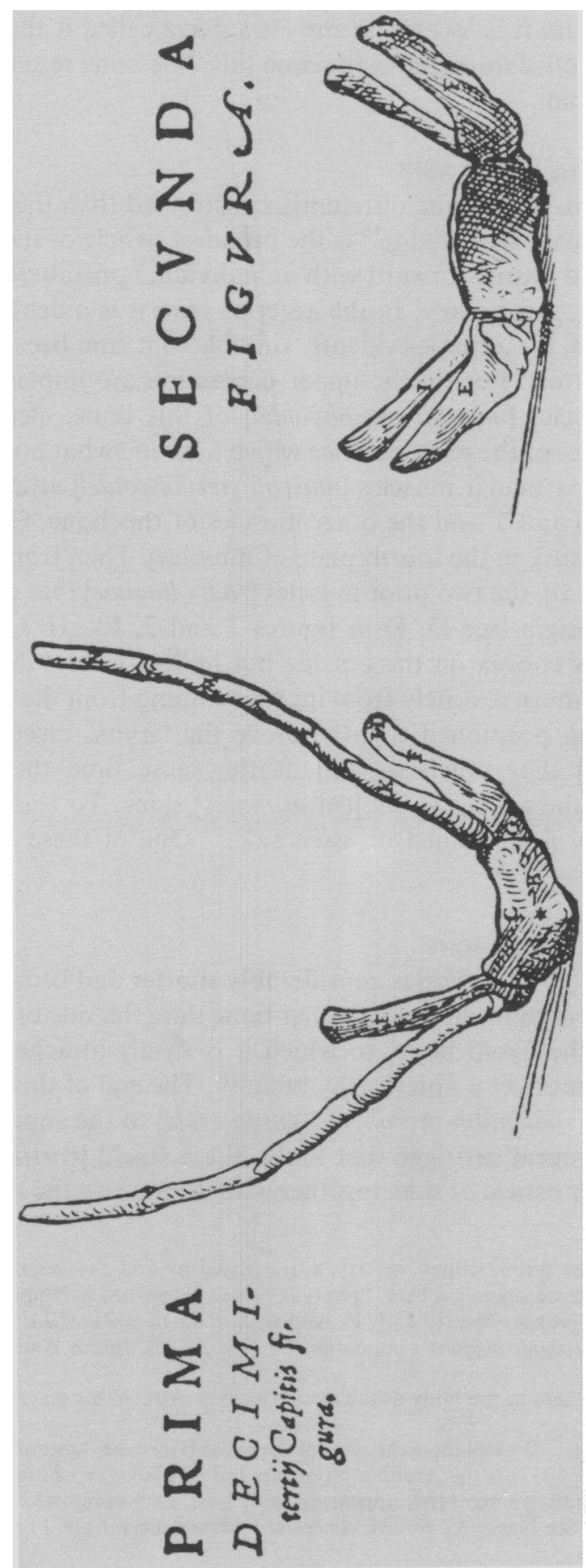

Plate A: The hyoid bone. 


\section{H. Garrison and M. H. Hast}

are some who, because it is located in the jaws, have called it the pharyngetron. ${ }^{15} \mathrm{I}$ have made it my practice throughout to name this "the bone resembling a v", or in a briefer word the hyoid.

\section{MIDDLE OSSICLE OF THE HYOID BONE}

The human has this bone quite differently constructed than the quadruped, which until now we have dealt with, and it $^{16}$ is the broadest ossicle of the hyoid bone, both swelling outward and jutting forward with an individual protuberance; but inside, or in the posterior seat, it is hollow. In the anterior seat, it is indented on top as in an elongated depression, for a shape evidently suitable to it, and because of muscles and ligaments attached to it. For on the upper depression are implanted the third and fourth peculiar muscles [musculi geniohyoidei] of this bone; clearly visible in this location near the sides of the protuberance which are somewhat hollowed in a bulging place, the first two particular muscles [musculi sternohyoidei] attempt their insertion into this bone (see $\mathrm{S}$ and $\mathrm{T}$ and the other muscles of this bone, $\mathrm{Q}$ [ $\mathrm{m}$. stylohyoideus] and V [ $m$. omohyoideus], in the fourth plate of muscles). Then from the hollow of the posterior aspect [bursa], the two prior muscles [radix linguae] that especially move the tongue have their origin (see D, D in figures 1 and 2, Bk. II. Ch. 19). Moreover, because the hyoid is convex on the outside but hollow inside, the muscles are also opportunely placed more remotely from injuries coming from the outside. The larger ossicle [cornu majus], positioned slightly above the larynx, meets the ones [cornua superiora thyroidea] that touch it, and at the same time these superior horns practically conceal themselves in its [cornu majus] sides. To this wider ossicle two others [cornua minora] are joined on each side. ${ }^{17}$ One of these is lower, the other higher.

\section{LOWER SIDES OF THE HYOID BONE}

The lower ossicle [cornu majus] is considerably shorter and broader than the upper [cornu minus], ${ }^{18}$ and is connected to no other bone than the side of the middle and the broader ossicle of the hyoid bone, to which it is firmly attached by cartilage and cartilaginous ligament over a noteworthy breadth. The end of this bone $(\mathrm{H}$ in figures 1 and 2) is joined [ligamentum thyrohyoideum laterale] to the superior process [cornu superius] of the laryngeal cartilage that looks like a shield [cartilago thyroidea]. We rightly call this lower ossicle or side, together with its mate on the other side, the lower

\footnotetext{
${ }^{15}$ A variant reading for $\phi \alpha \rho v ́ \gamma \gamma \varepsilon \theta \rho o v$, or larynx, translated by LSJ as $=\phi \dot{\alpha} \rho v \gamma \xi$, i.e. the windpipe or pharynx, but not in the sense suggested here, "pharynx-bone". The word is Hippocratic: De anatome 1.1; see also Galen, De libris propriis liber 19.28.1, Ps.-Galen, Introductio seu medicus 14.721.5, Aretaeus (2nd century AD), De causis et signis acutorum morborum 1.7.1-4, 2.2.1.3, Aetius Amidenus (6th century AD), Iatricorum liber 2.92.24.

${ }^{16}$ Vesalius is referring here to the body of the hyoid (marked ABC in his diagram) as distinct from the cornua.

${ }^{17}$ The 1555 edition adds: "We call these the sides of the hyoid bone with Avicenna, in his chapter 'On the Throat'." Avicenna (980-1037) is the Arabian physician and philosopher whose Canon of medicine had been considered authoritative since 1100 , appearing in at least sixty complete or partial Latin editions between 1500 and 1674. See Nancy G. Siraisi, Avicenna in Renaissance Italy, Princeton University Press, 1987.

${ }^{18}$ See note 10 above.
} 


\section{Andreas Vesalius on the larynx}

side [cornu majus] of the hyoid bone, fit for admitting and bringing forth a certain number of muscles [i.e., a fit point of origin and insertion]. And these lower sides, along with the middle or greater ossicle [corpus], nicely make the figure $v$.

\section{SUPERIOR SIDES AND ATTACHED OSSICLES}

Moreover, to the upper ossicle or side [cornu minus], which appears smoother, are joined in turn, long, rounded ossicles ( $L, M$, and $N$ in figure 1 ) in a continuous series, until their ends near the base of the process of the temporal bone, which we have often mentioned looks like a writer's stylus [processus styloideus], are inserted in the temporal bone, as can be seen most clearly in quadrupeds. ${ }^{19}$ These ossicles, attached to the superior sides of the hyoid bone, are not always observed in an equal number, as quite often they are seen three or four on each side. From time to time, however, especially in women, we have seen these ossicles ${ }^{20}$ and the upper sides missing altogether, and in their place a certain rounded, strong, elongated ligament [ $l$. stylohyoideum] attached to the hyoid bone and the stylus-like process. This has often been called to my attention by my good friend Realdo Colombo, ${ }^{21}$ now a professor of sophistic at Padua, a most diligent student of anatomy. The hyoid bone is therefore neither free-floating nor contiguous to any bone, as the superior sides connected to the temporal bones show. The lower sides also, attached by a ligament [membranea thyrohyoidea] to the processes of the shield-like cartilage, attest to the same fact. For the cartilages of the larynx, like the cartilages of the ribs, perform the function of bones and are counted in the class of bones, which has a bearing on their contiguity.

\section{HOW THE HYOID BONE IS STRENGTHENED; ITS USE}

Inasmuch as the hyoid bone rests on no base as firm as the other bones, we shall explain in Book Two that it is pulled easily into every variety of position by its own muscles, but in such a way that it can be dislocated from its place neither laterally, nor vertically, nor forward or backward. And though in humans it happens to be extremely small, it performs the greatest and most numerous functions; these will be explained when we show that several muscles of the tongue [ $\mathrm{mm}$. hyoglossi] originate from it, that it is placed beneath the tongue like a foundation and very steady base, and that certain beginnings of the muscles of the larynx [ $\mathrm{mm}$. thyrohyoidei] extend from it.

\footnotetext{
19 The 1555 edition omits this reference to quadrupeds, and adds that ossicles $\mathrm{L}, \mathrm{M}$, and $\mathrm{N}$ in figure 1 are also attached "to the upper surface of the middle of the side of the hyoid bone, as if it were attached from a point".

${ }^{20}$ See note 10 above.

${ }^{21}$ Vesalius' teaching assistant at Padua when Vesalius was writing the Fabrica, appointed to a chair in surgery in 1541. Born in Cremona $c .1515$, he was appointed to Vesalius' chair when his teacher left Padua in 1542. Colombo put forth his own views on anatomy in De re anatomica, Venice, N. Bevilacquae, 1559. See C. D. O'Malley, op. cit., note 6 above, pp. 109f.; R. J. Moses and C. D. O'Malley, 'Realdo Colombo: On those things rarely found in anatomy', Bull. Hist. Med., 1960, 34, 508-28; and Fielding H. Garrison, An introduction to the history of medicine, 4 th ed. Philadelphia, W. B. Saunders, 1929, p. 222. For the quarrel that led to the deletion of this reference from the 1555 edition, see O'Malley, p. 197.
} 
BOOK I

CHAPTER 38

\section{On the Cartilages of the Rough Artery, AND WHAT THEREIN WOULD BE CALLED BY THE GREEKS GLOTTIS AND EPIGLOTTIS}

The first figure of the thirty-eighth chapter represents the anterior face of the rough artery [trachea] free from all [adjacent] parts.

The second figure delineates the posterior face of the trunk of the rough artery. It would have been beside the point to draw in the series of branches reaching into the body of the lung for this figure as for the first, since the first figure presents it abundantly.

An index [follows] of the thirteen figures which are set forth here in order, and their letters.

The first of these figures, marked 3, shows the first cartilage [cartilago thyroidea] of the larynx from the right side; because it resembles a shield we will also call it the shield-shaped (scutiform). The figure which is fourth in order displays the inner or posterior face of the same cartilage. In the fifth is drawn the same cartilage in the outer or anterior face. The sixth represents the anterior face of the second cartilage [cartilago cricoidea] of the larynx. The seventh has the second cartilage of the larynx shown from the right side. The eighth presents the second cartilage of the larynx depicted from the posterior face. In the ninth is drawn the third cartilage [cartilago arytenoidea] of the larynx from the right side. ${ }^{22}$ In the tenth appears the anterior aspect of the third cartilage. The eleventh shows the same cartilage in its posterior face. The twelfth shows the lower [dorsal] seat of the operculum [epiglottis] of the larynx, where the operculum faces the bulk of the larynx. The thirteenth has the superior [ventral] seat of the operculum of the larynx, which faces the palate. The fourteenth offers to view from the anterior [and superior] or external face one cartilage of the trunk of the rough artery [trachea], built like the letter $\mathrm{C}$. The fifteenth shows the same cartilage in its posterior [and inferior] face, which faces the inner mass of the rough artery.

A, B 3, 4, 5: The two higher processes [cornua superiora] of the shield-shaped cartilage.

C, D 3, 4, 5: The two lower processes [cornua inferiora] of the same cartilage.

$\mathrm{E}, \mathrm{F}$ in 8 , but only $\mathrm{E}$ in 7 : Seat of the second cartilage [facies articularis thyroidea], where the lower processes of the shield-shaped cartilage unite (with the second cartilage).

G, H 3, 4, 5: At this point the shield-shaped cartilage is seen at its narrowest and smallest, now and again showing the line ${ }^{23}$ which separates the right portion [lamina dextra] of the cartilage from the left [lamina sinistra] as if they were two cartilages.

\footnotetext{
22 See page 15, where Vesalius acknowledges that the arytenoid is a double ("twin") cartilage.

23 This "line" is visible in the infant thyroid cartilage and is called the "intrathyroid cartilage"; the remnants (points $\mathrm{G}$ and $\mathrm{H}$ ) are named incisura thyroidea superior et inferior.
} 


\section{Andreas Vesalius on the larynx}

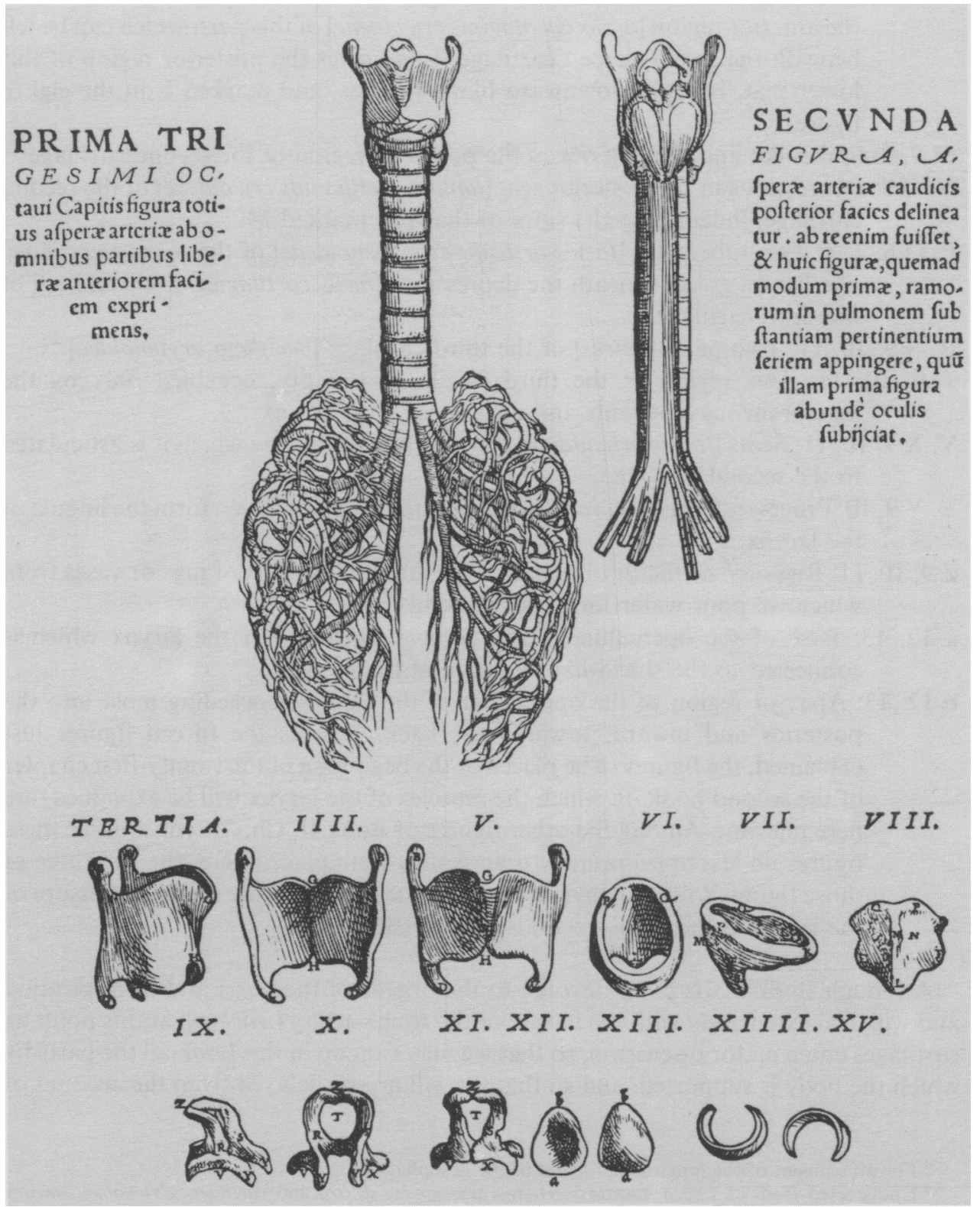

Plate B: Cartilages of the larynx. 


\section{H. Garrison and M. H. Hast}

I 6, 7: At these points is seen the area of the second cartilage facing the inner mass of the larynx. The remaining parts which are seen in these three figures constitute the outer region or mass of the larynx.

K, L 6, 7: The lower seat of the second cartilage, forming a complete circle. $\mathrm{K}$ marks the anterior region [arcus cartilaginis cricoideae] of this part, which can be felt beneath the shield-shaped cartilage. $L$ indicates the posterior region of this lower seat, brought downward like a process, and marked $\mathrm{L}$ in the eighth figure.

M 7, 8: Spine-like line sticking out in the posterior region of the second cartilage. ${ }^{24}$

$\mathrm{N}, \mathrm{O}$ 8: Depressions in the posterior seat [lamina cartilaginis cricoideae] of the second cartilage, indented at the sides of that line marked $\mathbf{M}$.

P, Q 6, 7, 8: Two tubercules [facies articulares arytenoideae] of the second cartilage, like heads, going beneath the depressions [basis cartilaginis arytenoideae] of the third cartilage.

R, S 9, 10, 11: Two parts [apices] of the third cartilage [cartilago arytenoidea]. ${ }^{25}$

$\mathrm{T}$ 9, 10, 11: This region of the third cartilage is empty, occupied only by the membraneous ligaments and coverings of the larynx.

$\mathrm{V}, \mathrm{X}$ 9, 10, 11: Seats [facies articularis] of the third cartilage by which it is articulated to the second cartilage.

Y, Y 9, 10: Processes [processus vocalis] of the third cartilage which form the lingula of the larynx.

$\mathrm{Z}$ 9, 10, 11: Region ${ }^{26}$ of the third cartilage resembling that part of jugs or vases from which we pour water for hand washing.

a 12, 13: Base of the operculum [cartilago epiglotticum] ${ }^{27}$ of the larynx which is connected to the shield-like cartilage of the larynx.

b 12, 13: Apex or region of the operculum of the larynx proceeding most into the posterior and inward, towards the back. Besides the fifteen figures just explained, the figures to be placed at the beginning of the twenty-first chapter of the second book, in which the muscles of the larynx will be explained, are here relevant. Among the other figures of Book II, Ch. 21, you will see these figures no less appropriately than if they were placed here; the last three of those figures will be included, in which the picture of the lingula or fissure of the larynx is drawn as accurately as possible.

Although Book Six is to be devoted to the organs of the heart and of respiration and will deal extensively with the nature of the rough artery [trachea], at this point its cartilages come up for discussion, so that we may sum up in this book all the parts by which the body is supported, and so that we will not be delayed from the account of

\footnotetext{
${ }^{24}$ For attachment of the longitudinal fibres of the oesophagus.

${ }^{25}$ Undissected from its tunica mucosa, cartilago arytenoidea dextra and cartilago arytenoidea sinistra

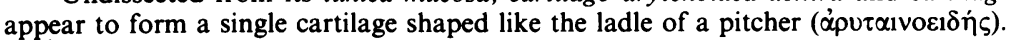

${ }^{26}$ Composed of cartilago corniculata discovered by Giovanni Santorini (1681-1737), articulating with the apex cartilaginis arytenoideae.

${ }_{27}$ Disproportionately and inaccurately illustrated in figures 12 and 13 ; more accurately proportioned (but more canine in its general aspect) in figure 2.
} 


\section{Andreas Vesalius on the larynx}

the muscles in the following book by the omission of bones and cartilages here. In the sixth book we will explain how the rough artery is led down from the pharynx into the bulk of the thorax and spread out by a multiple growth of branches [bronchi] into the lungs, so as to bring them air and take it out again. Not only do we depict this as an instrument of respiration, but also we will declare that it is the principal organ of the voice and then explain in exact detail the nature of its substance. For it is composed in part of cartilages, in part of ligaments and of simple membranes or tunicae, and finally of muscles peculiar to its own head [larynx].

\section{FIRST LARYNGEAL CARTILAGE [CARTILAGO THYROIDEA]}

This superior part of the rough artery [trachea] (which I would have thought should be called the larnyx rather than the throat) consists first of three cartilages, the first of which is the largest and broadest and is anterior, externally a hump [prominentia laryngea] but internally flattened, somewhat like a shield-not a round one but exceptionally long, such as we see the ancients used in their battles and still see some of the Turks use, especially in ships. And for this reason experts in dissection have called it $\theta u p \varepsilon o \varepsilon ı \hat{\eta}$ (thureoeide, i.e. shield-shaped) and laymen "shieldlike" (scutalis and peltalis), and likewise we also will regularly, when we talk about it, call it scutiform or cartilage like a shield-unless on the other hand it seems best to call this the first cartilage. In the human, it looks bigger in its superior seat than in the inferior, much different than in cattle and pigs, where it is wider in the inferior seat but much narrower in the superior, and is less extended forward into a point than the larynx of man. But what has a bearing on the appearance is that the human cartilage corresponds to itself on the superior and inferior seat. For it puts out two processes [cornua] each from both upper and lower sides, one on each side, and of these the two upper ones [cornua superiora] extend farther than the lower ones [cornua inferiora] and are attached by membraneous ligaments [ligamentum thyrohyoideum laterale] to the lower sides of the hyoid bone. The lower processes of the shieldlike cartilage are united to the sides of the second cartilage [cartilago cricoidea] towards its posterior seat, and join together. This shieldlike cartilage juts out more towards the front in men [prominentia laryngea] than in women, and is more exposed to the touch; and now and then, it is a twin, ${ }^{28}$ and it is especially observed in males. For in its middle, where the cartilage of humans is narrowest, and it protrudes most towards the front, a line is often extended along its longitude which when carefully cleaned of the fine membranes shows that two pieces of cartilage had been joined to each other even before the dissection. Now this is certainly unique to humans; the cartilage of cattle is simple, and the shape differs most from the cartilage of man. I should like this to be carefully observed by architects: for it is remarkable how the scutiform cartilage of cattle resembles the shape of a rampart, and how skilfully it is accommodated to lookouts in its higher seat (because of the special recesses cut into it), and how aptly aligned for deflecting the blows of artillery, just as if there were a certain portable machine which could be fixed into the ground by its two lower processes as by two stakes and placed in front of an army.

${ }^{28}$ Anomalous unfused thyroid laminae. 


\section{H. Garrison and M. H. Hast}

SECOND LARYNGEAL CARTILAGE [cartilago cricoidea]

The second cartilage is smaller than the first and larger than the third [cartilago arytenoidea], and the greatest part of it is placed back in the posterior seats of the larynx where the food passage (which we will call the stomachus with the Greeks ${ }^{29}$ ) [cavitas pharyngis] is brought downward from the jaws. For as much as the scutiform cartilage falls short of being a perfect figure of a circle, to that degree this second cartilage completes a circle in its superior and posterior part. In its lower seat it completes a perfect circle whose anterior part beneath the root of the scutiform cartilage we perceive by touch in the frontal seat of the larynx. The inner extent of this cartilage is perfectly smooth, while its posterior seat facing the gullet bulges in a long line following the longitude of the cartilage as if stretched out in the manner of a thorn (spina).$^{30}$ This [projection] separates the two recesses of this cartilage in which are fixed two muscles [musculi crico-arytenoidei posteriores] attached in a straight line from the second cartilage into the third. The superior seat of this cartilage, where it forms the posterior region of the larynx, comes to an end in two oblong tubercles [facies articularis arytenoidea] ( $\mathrm{P}$ and $\mathrm{Q}$ in figures $6,7,8)$, one on each side, which you will soon hear are articulated into the ends of the third cartilage ( $V$ and $X$ in figure 10) [basis cartilaginis arytenoideae]. Also, this second cartilage is joined to the first in the manner explained above, when I was saying that the lower processes of the first cartilage [cornua inferiora] join together with it. Indeed, so that the connection of these processes will be stronger, the second cartilage swells slightly ( $E$ and $F$ in figure 8) at the point [facies articularis thyroidea] where the processes join it, and is thicker; in this protuberant part is seen the recess which receives the process of the first cartilage with great strength ( $\mathrm{L}$ in figures $6,7,8$ ). The lower portion of the second cartilage, where it constitutes the posterior of the larynx, appears quite thin, more stretched out below than the remaining seat of its inferior part. This is so that the muscles may take their beginning from a more remote seat, stretched straight along the longitude of the second cartilage and inserted into the third cartilage. To this [second] cartilage no name has been applied, and for this reason it will be called by us with a special name, the Unnamed [Innominata or innominate]. But if someone carefully examined its appearance and wished to compare it to the shape of something and finally from that to give it a name, he would discover nothing more fitting to it than that ring of the Turks, which they put on their right thumb when shooting the bow, so that with the aid of that ring they may pull the bowstring harder. For this ring, in the part where it faces the inside of the thumb, resembles the anterior seat of the second cartilage. But where it covers the outer seat of the thumb, it is more or less like the posterior region of the second cartilage, as it is possible to see from the picture of a ring which I provide in the margin.

\section{THIRD LAR YNGEAL CARTILAGE}

The Greeks called the third cartilage of the larynx (figures 9, 10, 11) arytaina and arytainoeidés $^{31}$ (ladle, or ladle-shaped) [cartilago arytenoidea], which when it is still in

${ }^{29}$ As early as Homer, $\sigma \tau o ́ \mu \alpha \chi o \zeta=$ throat; later (Plutarch, Galen), the orifice of the stomach.

30 The oesophagus is attached to the spine or vertical ridge of the lamina of the cricoid cartilage by tendo cricooesophageus.

${ }^{31}$ See Galen, De usu partium 3.553-588, May, pp. 353f. The 1555 edition adds that some of the Latini call this the gutturnium. 


\section{Andreas Vesalius on the larynx}

one piece and still overlaid by the membrane or tunic surrounding the rough artery inside [tunica mucosa], would be very like that part of a pitcher with which we pour water for hand washing. For it more closely resembles that part of the mouth of jugs [i.e. the spout] than those wooden shell-shaped vessels with which we see sailors empty bilge-water, ${ }^{32}$ or vegetable farmers water gardens. At any rate, if the Greeks seem to have compared this cartilage to vessels or small containers of this type, ${ }^{33}$ it was not indeed to the entire vase, but to its tip. ${ }^{34}$ However that may be, all the professors of dissection have described the third cartilage of the larynx as single and simple, though at the same time when freed from its membranes, it is twin; and it is made up of two cartilages ( $R$ and $S$ in figures $9,10,11$ ), albeit mutually somewhat loosely joined, thanks to the ligaments and the membrane surrounding the larynx. One of these [halves of the arytenoid cartilage] rests upon the right side of the second cartilage, the other on the left [facies articularis arytenoidea] $(\mathrm{Q}$ and $\mathrm{P}$ in figures 6, 7,8, $\mathrm{V}$ and $\mathrm{X}$ in figures 10,11 ), occupying a slight and rather deeply engraved depression, by which it accepts the tubercle of the second cartilage; and so it is articulated so that it can be moved to the inner space of the larnyx and then again away from it. This is the most mobile of all the cartilages of the larynx. The base of either cartilage is broad, and comes to an end in its anterior seat in a long process ( $\mathrm{Y}$ in figures 9 and 10) [processus vocalis] extending into the interior of the larynx. The upper parts of these cartilages $(\mathrm{Z}$ in figures $9,10,11)$ [cartilago corniculata dextra/sinistra], ${ }^{35}$ gradually opening apart on each side from the base ( $T$ in figures 10 and 11) [incisura interarytenoidea], and then becoming thinner and softer and rendered adipose, are joined together, and the upper part of the right cartilage being joined to the [corresponding] part of the left cartilage forms that seat of the larynx that matches the part of vases by which, we mentioned above, water is poured for the hands. Now in fact this part of the larynx is so soft and pliable that when people vomit it is bent forward into the inner space of the larynx and so perfectly covers the rough artery [the glottis] that not even the least of the vomit slips into the artery itself. And if in other respects this third cartilage is a twin constructed of two cartilages, yet we will not for that reason count it as two cartilages; but it will be considered just a single cartilage by me as it is by the other anatomists, and will be called the third, so that I might not seem unreasonably to confuse the opinions of those who have numbered rather than described the cartilages.

\section{OPERCULUM OF THE LARYNX}

To these three cartilages of the larynx another one joins [cartilago epiglottica] (figures 12 and 13), soft and in substance quite similar to the upper part of the third cartilage, which quite elegantly forms the covering of the larynx, carefully keeping any food or drink from running down into the larynx. This covering of the larynx is made wide and curved towards the front at the base (a in figures 12 and 13), away

\footnotetext{
32 The 1555 edition substitutes the more edifying picture of washing sails.

${ }^{33}$ Several Greek words for "pitcher" were used in an anatomical sense for the various cavities of the body,

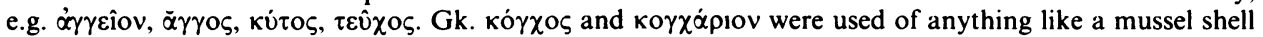
(not to be confused with Eng. conch), e.g. the hollow of the ear, the socket of the eye, the knee-pan.

${ }^{34}$ See note 26 above.

${ }^{35}$ See note 27 above.
} 


\section{H. Garrison and M. H. Hast}

from the inner region of the scutiform [cartilago thyroidea] next to its higher part; proceeding hence inwards ( $b$ in figures 12 and 13), it has a triangular appearance, ${ }^{36}$ the base of the operculum [petiolus epiglottidis] rising from the scutiform [thyroid] cartilage, or it forms its own triangular shape when connected [by the ligamentum thyro-epiglotticum] with that cartilage. The apex of the triangle is that part which is drawn inside as if to the region of the gullet. Where this body faces the palate, it is bulging and softer; but where it pushes on the larynx it is hollow and flattened, and much harder than on its upper part. In its farthest part, where it faces the gullet, it is remarkably soft, and overlaid by a fatty membrane it somehow recalls the nature of a ligament; ${ }^{37}$ but where it is joined to the scutiform cartilage, there is a great deal of fat, ${ }^{38}$ and there it does not seem as hard as in its middle. Most have thought that this is the especial organ of the voice, terming it haphazardly glöttis and epiglottis: but these names are completely contradictory and they signified completely different parts to the ancient professors of anatomy.

\section{LINGULA OF THE LARYNX, OR FISSURE AND PARTICULAR ORGAN OF THE VOICE}

For glottis denotes the fissure [rima glottidis] of the larynx which the two processes of the third cartilage [processus vocales] (Y, Y in figures 9 and 10) make when covered by the fatty membrane [tunica mucosa] in the middle space of the larynx, and which we will show in the fifth book is the particular organ of the voice. They called that kind of fissure glöttis or lingula [plica vocalis] from its resemblance to tongue-like devices which we see assembled out of two layers of reed when a reeded pipe is put together. The other term epiglottis is the name for the covering of the larynx, placed over what we just now called the lingula of the larynx and preventing any food from falling inside it. Now the fact that this is hidden from doctors of our time is not so much their fault, occupied as they are with nothing except the ideas of [ancient] authors who have no experience of dissection. Indeed, even Celsus ${ }^{39}$ misunderstood this matter (as he did a very large number of things having to do with anatomy) and called the operculum of the larynx the lingula, not considering that this had been called epiglottis by the Greeks, because it rests upon the fissure of the larynx which we compare to the lingula of reed-pipes; or he ignored the fact that there is another place or part in the larynx besides the operculum which we might compare to a little tongue. This operculum also somewhat resembles the human tongue. Moreover, Theodorus $\mathrm{Gaza}^{40}$ misled by the error of Celsus, translated Aristotle's epiglöttis ${ }^{41}$ as lingula, though at the same time Aristotle meant the operculum of the larnyx but not the part or seat which the ancients called the lingula [plica vocalis] and which is rightly

${ }^{36}$ The 1555 edition notes that Hippocrates compared it to an ivy leaf.

${ }^{37}$ The 1555 edition adds that "in its upper part it resembles in substance the third cartilage".

${ }^{38}$ Adipose tissue between ventral surface of epiglottis and ligamentum thyrohyoideum medianum.

39 Aulus Cornelius Celsus, an encyclopedist of the first century AD, whose writing on medicine was based on Hellenistic doctrines. Known as the Cicero medicorum, his Latin "became the model of Renaissance writing when his book, almost unnoticed in antiquity and in the Middle Ages, was rediscovered and printed at a very early date"-Ludwig Edelstein in The Oxford classical dictionary, ed. N. G. L. Hammond and H. H. Scullard, 2nd ed., Oxford, Clarendon Press, 1970.

40 Theodorus Gaza (d. 1478) translated Aristotle's On the parts of animals into Latin. The 1555 edition adds here that Celsus "was perhaps the one who compared the operculum of the larynx to a human tongue".

${ }^{41}$ Vesalius cites here Aristotle De partibus animalium, chapter 3; see 664b.25-665a.9. 


\section{Andreas Vesalius on the larynx}

considered the principal instrument of the voice. I will pass over how many times in Galen, both by the fault of the translators and of the writers of the Greek exemplar, $\gamma \lambda \omega \tau \tau \imath \varsigma$ is read for $\dot{\varepsilon} \boldsymbol{\gamma} \gamma \lambda \omega \tau \tau i \zeta$ and vice versa. ${ }^{42}$ But I will pursue this subject more fully in the appropriate place: here it suffices to have treated of the cartilages of the larynx so far as we need for the discussion of muscles in the second book.

\section{OTHER CARTILAGES OF THE ROUGH ARTERY}

I will proceed in the same manner with the remaining cartilages of the rough artery (figures 14 and 15), which more or less resemble our letter C [cartilagines tracheales], together with everything pertinent to the rough artery, in Book Six. Now it will be timely to append the method and manner by which bones and cartilages are prepared for teaching, or are studied in Anatomy, viz. in accordance with the system by which I will always append after a description of the parts the prescribed method of dissecting them (as I consider appropriate to each occasion). ${ }^{43}$

\section{BOOK II CHAPTER 21}

\section{ON THE Muscles OF THE LARYNX}

Since, in the complete plates of the muscles placed in a series at the beginning of this Book, all the muscles of the larynx were unable to be placed on view, I have thought it not beside the point to exhibit the muscles of the larynx separately at the beginning of this Chapter, in this collection of figures.

The first figure represents the anterior aspect of the bone resembling the letter $v$ [os hyoideum], freed of all its muscles, together with the front of the larynx and the seat of the stem of the rough artery [trachea] (which is in the neck), with no muscle of the larynx resected. What muscles are clearly visible here, the index of characters will clearly explain.

The second figure shows the same as the first from the right side, though here we have kept not so great a portion of the stem of the rough artery, and we have also resected the upper sides [cornua minora] of the bone resembling the letter $v$.

The third corresponds completely to the second, except that this one portrays from the posterior surface those things that the former did from the side, and here also the upper sides of the hyoid bone are still deliberately represented.

The fourth sets forth the anterior seat of the larynx with a portion of the stem of the rough artery, with the hyoid bone now resected, as well as the muscles [ $m$.

\footnotetext{
42 Vesalius cites here "especially" Book 8 of Galen's De usu partium. For the confusion of glottis and epiglottis, see May, p. 688, n. 16. Galen's principal discussion of the glottis falls in 3.562-567, May, pp. $357-361$, of the epiglottis in 3.586-588, 594, May, pp. $372 \mathrm{f}$.

${ }^{43}$ Vesalius rewrote this section in the 1555 edition to read: "The remaining cartilages, which more or less resemble our letter $C$, and which later occur in succession under the larynx through the entire stem of the rough artery and all the scattered branches in the body of the lung itself, together with others belonging to the investigation of the rough artery, will be treated in the sixth book."
} 


\section{H. Garrison and M. H. Hast}

sternothyroideus, $m$. thyrohyoideus] ${ }^{44}$ brought forward from it and from the chest bone [sternum] to the larynx. And so the fifth and sixth of the common muscles of the larynx [ $\mathrm{mm}$. constrictores pharyngis inferiores] are preserved, in addition to the muscles [ligamentum hypoepiglotticum ${ }^{45}$ ] particular to the operculum [epiglottis] of the larynx.

The fifth figure does not differ from the fourth in the order of dissection, offering the same objects of scrutiny as the fourth but from the left side.

The sixth is the larynx freed from the rest of the stem of the rough artery, represented in its posterior surface so that I would leave out no portion of the gullet [oesophagus] or of any common muscle [e.g., m. constrictor pharyngis inferior], and at the same time we have removed no cartilage of the larynx from its place. ${ }^{46}$

The seventh contains the larynx so represented from its right side that its covering [epiglottis] is now resected, together with the muscles [ $\mathrm{mm}$. cricothyroidei] connecting the second cartilage [cricoid] to the first [thyroid]. Also, on this side the lower process [cornu inferius] of the first cartilage [thyroid] has been freed from the second cartilage, and this same first cartilage is bent forward away from the second so that the middle seat of the first cartilage may be seen bare in the posterior region.

The eighth differs from the seventh in this way, that here we have cut back the four [sic] straight muscles [ $\mathrm{mm}$. cricoarytenoidei posteriores] of those that bind the third cartilage [arytenoid] to the second [cricoid], and the second cartilage shows more uncovered.

The ninth differs again from the eighth in that beyond the muscles just now mentioned, we have taken away the four [sic] oblique muscles [ $\mathrm{mm}$. cricoarytenoidei laterales] of those joining the third to the second cartilage, and in addition the two [ $\mathrm{m}$. arytenoideus transversus $]^{47}$ located in the base of the third cartilage, but keeping, along with the three cartilages, those muscles [ $\mathrm{mm}$. thyroarytenoidei] that bind the third cartilage to the first.

The tenth shows the front of the larynx with the first cartilage now removed and, appearing with only the second and third cartilages, the muscles [ $\mathrm{mm}$. thyroarytenoidel] joining the third cartilage with the first.

The eleventh is not intended to show the muscles of the larynx, but we have drawn this, and the two which follow, to display the tongue [plica vocalis] of the larynx. ${ }^{48}$ Therefore the larynx is drawn here free from the remaining trunk of the rough artery [trachea] and from its common muscles; its operculum [epiglottis] is still preserved, it rests on its posterior [sic; anterior] surface, and it shows its superior [sic; posterior] surface.

The twelfth differs from the eleventh in that it represents the lower seat of the larynx.

\footnotetext{
44 The "extrinsic muscles" of the larynx.

45 A single ligament in the human: "it is exceedingly rare as a human muscle [ $m$. hyoepiglotticus], though common in other animals [m. levator epiglottidis]."-A. Macalister, Transactions of the Royal Irish Academy, 1875, 25: 31 .

46 The epiglottis, marked $\mathrm{L}$ in this figure, is canine.

47 The transverse arytenoid muscle is a single, unpaired muscle, unlike the other intrinsic laryngeal muscles. Vesalius' illustration of this muscle (V in figures $6,7,8$ ) resembles that of the dog, in which the right and left halves are joined by a tendon.

${ }^{48}$ Although not identified by Vesalius, aryepiglottic folds are shown in this figure.
} 


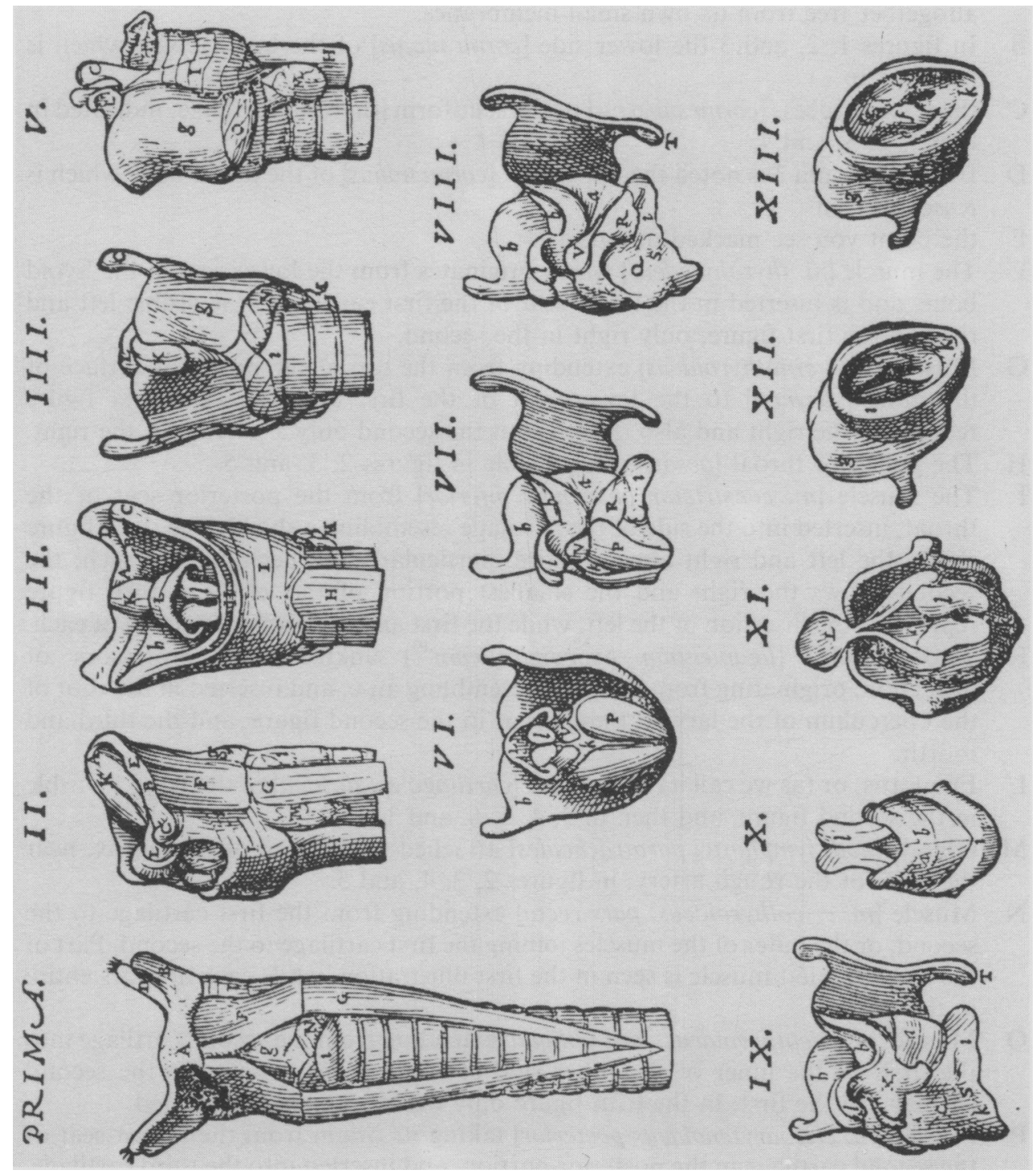

Plate C: Muscles of the larynx. 


\section{H. Garrison and M. H. Hast}

The thirteenth has this distinction from the twelfth, that it portrays the fissure or lingula [rima glottidis] of the larynx more narrowed or occluded. The index of the characters will be as follows.

A In the first, second, and third figures is marked the face [corpus] of the hyoid, not altogether free from its own small membranes.

B In figures 1, 2, and 3 the lower side [cornu majus] of the hyoid bone, which is attached to

C the upper process [cornu superius] of the scutiform [thyroid] cartilage, indicated in figures 2,3 , and 4 .

D In figures 1 and 3 is noted the upper side [cornu minus] of the hyoid bone which is resected from

E the point you see marked in figure 2 .

F The muscle [ $m$. thyrohyoideus] which originates from the lower seat of the hyoid bone, and is inserted in the lower seat of the first cartilage. It is visible left and right in the first figure, only right in the second.

G Muscle [ $m$. sternothyroideus] extending from the top of the posterior surface of the bone [sternum] to the lower seat of the first cartilage. The first figure represents the right and also the left, but the second only a portion of the right.

$\mathrm{H}$ The gullet, or throat [oesophagus], visible in figures 2, 3, and 5.

I The muscle [ $m$. constrictor pharyngis inferior] from the posterior seat of the throat, inserted into the side of the cartilage resembling a shield. The third figure shows the left and right almost entire, particularly the beginning of each; the second shows the right and the smallest portion of the left. The fifth figure represents the insertion of the left, while the first and fourth the insertion of each.

$\mathrm{K}$ Two muscles [ligamentum hyoepigloticum ${ }^{49}$ ] unknown to professors of dissection, originating from the bone resembling an $v$, and inserted in the root of the operculum of the larynx; these occur in the second figure, and the third and fourth.

L Epiglottis, or (as we call it) operculum [cartilago epiglottica] of the larynx, visible in the second figure, and then in $3,4,5,6$, and 11 .

M Glands [nodi lymphatici paratracheales] attached to the root of the larynx, near the sides of the rough artery, in figures $2,3,4$, and 5 .

$\mathrm{N}$ Muscle [ $\mathrm{m}$. cricothyroideus, pars recta] extending from the first cartilage to the second, or the outer of the muscles joining the first cartilage to the second. Part of the right and left muscle is seen in the first illustration, while each appears entire in the fourth.

O Muscle [ $m$. cricothyroideus, pars obliqua] extending from the second cartilage into the first, or the inner of the other side of the muscles connecting the second cartilage to the first; in the fifth figure only the left one is represented.

P Muscle [ $m$. cricoarytenoideus posterior] taking its origin from the lowest seat of the second cartilage in the posterior portion, and inserted into the third cartilage. The sixth figure shows left and right, the seventh the right and to some degree the left.

Q Seat of the muscle just mentioned, in the eighth and ninth figures [lamina cartilaginis cricoideae].

${ }^{49}$ See note 45 above. 


\section{Andreas Vesalius on the larynx}

R Muscle [ $m$. cricoarytenoideus lateralis] from the side of the second cartilage, inserted in the third cartilage. The seventh and eighth figures show only the right.

$\mathrm{S}$ The depression [facies articularis thyroidea] of the second cartilage is marked in the eighth and ninth figures, to which

$\mathrm{T}$ the lower process [cornu inferius] of the first cartilage, marked in the eighth and ninth figures, articulates.

V Muscle [ $m$. arytenoideus transversus $]^{50}$ sited in the base of the third cartilage. The sixth figure represents the muscle of each side, the seventh the right and a small portion of the left, the eighth the right.

$\mathrm{X}$ In the ninth figure is marked the depression [processus muscularis] in which lies the muscle occupying the base of the third cartilage [arytenoid] on one side, marked with the letter $\mathrm{V}$.

a Muscle [ $m$. thyroarytenoideus] originating out of the total length of the first cartilage and inserted in the third, or

b muscle [ $m$. thyroarytenoideus] connecting the third to the first cartilage. The tenth figure shows the right one marked a, the left one marked $b$, with the first cartilage removed. The seventh, eighth, and ninth illustrate the whole muscle of the right side marked a, and the upper portion of the left, which for this reason also I have noted in those figures with the letter $b$.

c The upper surface of the lingula or fissure [plica vocalis] in the middle of the exposed larynx, is seen in the tenth figure.

d The lower surface of the lingula [plica vocalis], which we have shown more open in the thirteenth figure than in the twelfth.

e, e Two depressions, one on each side, which when the lingula [rima glottidis, pars intermembranacea] or fissure is closed come out visibly in its lower seat, in the twelfth and thirteenth.

f Induration [vocal nodule] appearing in the middle of the fissure where it closes the most, in the thirteenth.

g Lest, perhaps, cartilages not marked by letters introduce some obscurity, we will mark them also. And so $\mathrm{g}$ is the first cartilage [thyroidea] presenting itself in its anterior portion [lamina] in figure 1 , then in $2,4,5,12,13$.

$\mathrm{h}$ The first cartilage, presenting itself in its posterior surface in the third figure and in $6,7,8,9$.

i The second cartilage visible in its anterior surface [arcus cartilaginis cricoideae] in the first, 2, 4, 5, 7, 8, 9, 10, 12, 13.

k The second cartilage is seen in its posterior surface [lamina cartilaginis cricoideae] in the sixth, $7,8,9,11,12,13$.

1 The third cartilage [arytenoidea] occurs in the second, 3, 6, 7, 8, 9, 10, 11. ${ }^{51}$

I described the three cartilages of the larynx in the previous Book, counting the third cartilage [arytenoid], even though it be double, as a single one to avoid altogether confusing the opinions of other professors of anatomy. In addition, I

\footnotetext{
50 See note 47 above.

51 The letter " $\Gamma$ " is placed on that part of the arytenoid cartilage that is designated cartilago corniculata in modern anatomical terminology.
} 


\section{H. Garrison and M. H. Hast}

reported that a similarly cartilaginous body, but yet endowed with a fatty and membraneous substance, lay upon these cartilages; it is called epiglottis. At the same time, I recorded that the glottis, a certain body or rather seat of the larynx, is located in its midst, quite similar to the small crack or fissure [rima glottidis] of the reeds [plica vocalis] through which reed-pipes are played. Now I shall examine the muscles of these cartilages, as I shall explain their nerves separately in the fourth Book. Since, therefore, the larynx is constructed from several cartilages so that it may be tightly closed and opened, and because the breath, when it is held and when we speak, ought to move [the glottis] by voluntary motion, and from our interrupted flow of air, Nature justly imparted to the larynx the motor muscles of the cartilages, some of which are peculiar to the larynx alone, others [e.g. musculi sternothyroidei et thyrohyoidei] common to other parts also. ${ }^{52}$

\section{THE TWELVE PARTICULAR (INTRINSIC) LARYNGEAL MUSCLES}

The human larynx is endowed with twelve [muscles] of its own, and of these four [ $\mathrm{mm}$. cricothyroidei, pars recta et pars obliqua] join the first cartilage, which we call the scutiform (shield-shaped), to the second, which is the innominate [cricoid]; four [ $\mathrm{mm}$. cricoarytenoidei laterales, $\mathbf{m m}$. cricoarytenoidei posteriores] connect the second to the third [arytenoid], two [ $\mathrm{mm}$. thyroarytenoidei] couple the third to the first, and two [ $\mathrm{m}$. arytenoideus transversus] ${ }^{53}$ have their seat in the base of the third cartilage where it is articulated to the second. Galen counted eight common muscles, but he explained only the six that are attached to the scutiform [thyroid] cartilage alone but not to the two other cartilages. Besides these six, I have observed two others [ $\mathrm{mm}$. arytenoidei obliqui, partes aryepiglotticae], not in fact connected to the scutiform [thyroid] cartilage but to the very operculum [epiglottis] of the larynx; for this reason, these do not come up for mention among the muscles which Galen called the common laryngeal muscles. Of what sort these are I will soon explain in order along with the rest, when I have taken up my discussion from the particular muscles, which were all engendered by the Maker of things to open or close the lingula [glottis] of the larynx. ${ }^{54}$

\section{INTRINSIC MUSCLES $1-4$}

And so, of the four [ $\mathrm{mm}$. cricothyroidei, partes rectae et partes obliquae] joining the first to the second cartilage, there are two on each side (one is $\mathrm{N}$ in figures 1 and 4, the other is $\mathrm{O}$ in figure 5) leading to the lower parts of the larynx, in its forward portion towards the sides. These are short but wide, thin and fleshy; one lies over the other, and they cut between each other with fibres resembling the letter $\mathrm{X} .{ }^{55}$ The exterior one

\footnotetext{
52 The 1555 edition rephrased the end of this sentence: ". . . Nature justly imparted to the larynx the motor muscles of the cartilages, some of which, both for origins and insertions, are attached only to cartilages and are therefore called particular to the larynx; while others, originating from other parts, are inserted in the cartilages of the larynx and its operculum, and are generally for that reason called common."

53 See note 51 above.

54 The 1555 edition omits the reference to Galen's De usu partium (3.558.16, May, p. 356), and substantially abbreviates the final two sentences of this section to read "We count eight common muscles, six inserted in the first cartilage and two in the operculum of the larynx. I shall now take them up in order of type, having begun my account from the intrinsic muscles."

55 The outline of these muscles "resembles" the letter $X$ as drawn in figure 4.
} 


\section{Andreas Vesalius on the larynx}

[pars obliqua] takes the origin of its fibres from the lower seat of the first cartilage; these fibres proceed obliquely downwards in a forward direction and are inserted in the part of the second cartilage that faces forward. The interior [muscle] [pars recta] lying beneath this, in the origin and course of its fibres similar everywhere to the exterior [muscle], takes its origin from the seat of the second cartilage, which is beneath the first, and is implanted in the lower seat of the first cartilage. Its fibres ascend from the back part obliquely forward. These four muscles, two on a side, corresponding closely to the intercostal muscles, adduct the first and second cartilage in turn as they close the fissure [space between thyroid and cricoid cartilages, anteriorly $^{56}$ of the larynx. From time to time, and not infrequently in my lectures, I have pointed out these four muscles, placed in just this way; sometimes, however, I have found only one on each side, keeping the orientation of the fibres of the anterior [pars recta] muscle described here, but at the same time it is a little thicker. But again, when I have observed only the second one [pars recta] to be present, not once and especially in males, I have observed two slender but fleshy muscles originating from the middle longitude of the ridge (spina) of the second cartilage (Plate B, M in figures 7 and 8), then extending obliquely downward, bringing about their insertion in the lower processes [cornu inferius] of the first cartilage (Plate B, C and D in figures 3,4 , and 5).

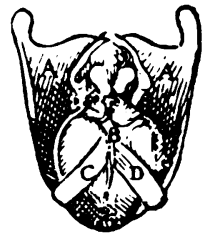

Plate D: The present figure corresponds to the sixth figure at the beginning of this chapter, except that this exhibits the muscles to be seen separately, which I have sometimes seen leading down to the lower processes of the first cartilage. The first cartilage of the larynx [thyroid] is labelled A and A; B the ridge of the second cartilage [cricoid], $\mathrm{C}$ and $\mathrm{D}$ the two muscles taking their origin from the spine of the second cartilage and inserted in the first cartilage. ${ }^{57}$

Moreover, these muscles clearly were also attaching the first cartilage more closely to the second, thereby tightening that fissure of the larynx.

INTRINSIC MUSCLES 5-8

Of the four muscles joining the third cartilage to the second [musculi cricoarytenoidei laterales et musculi cricoarytenoidei posteriores], there are two on each side ( $R$ and $P$ ), of which one ( $P$ in figures 6 and 7) [m. cricoarytenoideus posterior] is located in the total posterior seat of the second cartilage following its longitude where it faces the gullet [oesophagus]; it originates, with a fleshy beginning, from the lowest part of the second cartilage, and then proceeding straight up it broadens out until it is inserted by a sinewy implantation into the seat of the third cartilage (they are joined to $\mathrm{V}$ and $\mathrm{X}$ in Plate $\mathrm{B}$, figures 10-11) [cartilago arytenoidea, facies posterior] where it is articulated to the second. Through the length of the second cartilage, where it runs ( $\mathrm{N}$ or $\mathrm{O}$ in figure 8 , Plate B) [lamina cartilaginis cricoideae], so great a depression is carved out for this muscle that when it is removed on either side, the second cartilage seems to shrink away at that point into a sharp line ( $M$ in figure 8 ,

${ }^{56}$ Like the visor closing down in a knight's helmet.

${ }^{57}$ Anomalous pair of muscles, designated m. ceratocricoideus or Merkle's muscle (1857), but first described by Tourtual in 1846 (A. Macalister, Transactions of the Royal Irish Academy, 1875, 25: 28). 


\section{H. Garrison and M. H. Hast}

Plate B) like the ridge of the back vertebrae. Another muscle ( $R$ in figures 7 and 8 , Plate C) [ $m$. cricoarytenoideus lateralis] now contiguous to the one just now mentioned, and fleshy throughout, originates from the seat of the second cartilage which faces the inner region of the first cartilage, and admits the lower process (cornu inferius] of the first cartilage ( $\mathrm{T}$ to $\mathrm{Q}$ [lamina cartilaginis cricoideae, facies articularis thyroidea] in figure 8 and 9). And so from this seat the present muscle, taking a fleshy and broad origin and stretching obliquely upward, is inserted in the third cartilage, occupying the entire seat of its own side of the root of the third cartilage not taken up by the prior muscle [m. cricoarytenoideus posterior]. These four turn the third cartilage on both sides backward to the outside of the larynx, opening the lingula [glottis] or, if you will, the larynx itself. Also, the two first muscles [m. cricoarytenoideus posterior], occupying the posterior seat of the second cartilage, ${ }^{58}$ bring it about by their direct motion, and the rest also, that they are endowed with an oblique location, and so also obliquely turn the third cartilage to the rear.

\section{INTRINISC MUSCLES 9 AND 10}

The ninth and tenth muscles [mm. thyroarytenoidei], which couple the third to the first cartilage, are single broad muscles on each side ( $a$ and $b$ respectively in figures 8 , 9, and 10) and are fleshy, like the others of the larynx. They originate next to each other out of the middle seat [angle] of the first cartilage ( $\mathrm{G}$ and $\mathrm{H}$ in figure 4, Plate $\mathrm{B}$ ) along the entire length of its internal seat. The right one (understand the same about the left) shows its beginning as if it were triple because of certain marks so impressed upon it that by their presence the muscle seems triple. It climbs obliquely upward from its source and is implanted in the right front of the third cartilage [processus vocalis]. By these two the third cartilage is adducted to the first, and thanks to them the two parts of the third cartilage [processus vocalis] (Y, Y in figure 9 and 10, Plate B) come together when the muscles are contracted, and the lingula (vocal fold, plica vocalis] itself is adducted (shortened) very much with their aid. These muscles, with the temporal [m. temporalis], perform the mightiest task of all in the whole body in proportion to their size, since in holding the breath they [mm. thyroarytenoidei] are opposed by so many muscles forcing expiration, although here also the other muscles tighten the larynx [close the rima glottidis].

\section{INTRINSIC MUSCLES 11 AND 12}

The eleventh and twelfth $[\text { m. arytenoideus transversus }]^{59}(\mathrm{~V}$ in figures 6,7 , and 8$)$ are located in the base of the third cartilage in the region where the larynx is joined to the throat [oesophagus] ( $\mathrm{H}$ in figures $2,3,5)$ and the third cartilage is articulated to the second. They are single muscles from each side which take their origin from the base of the third cartilage where it is nearest to the first, and extending slightly upward along the base of the third cartilage, they end near the middle of the third cartilage (where its two parts are mutually joined), coming into contact with each other at this point. And so they are short, effective muscles, rounded on the outside somewhat in

\footnotetext{
58 The 1555 edition adds parenthetically that the second cartilage "is carved out longitudinally along each side to accommodate these muscles and projects in a sharp line along the middle, like the dorsal spine".

${ }^{59}$ See note 47 above.
} 
the manner of a pear, but on the inside throughout they are connected to the third cartilage, and where they meet they are wider and thicker than at their origin. Both muscles adduct the base of the third cartilage, and as they in turn compress the two parts of it, they close the lingula [rima glottidis, pars intercartilaginea], and tighten it. These too assuredly tend to show that the third is necessarily a twin cartilage, since if it were a single piece it could not be tightened by these muscles; and it follows, it could neither have been occluded by the two muscles joining the third to the first cartilage [mm. thyroarytenoidei] ( $\mathrm{a}$ and $\mathrm{b}$ in figures $7,8,9,10$ ), nor opened by the four connecting the third to the second cartilage $[\mathrm{mm}$. cricoarytenoidei posteriores et laterales] ( $\mathrm{P}$ and $\mathrm{R}$ in figure 7). Therefore, out of the twelve intrinsic muscles of the larynx, eight close it: four connecting the first to the second, two joining the third to the first, and finally two located in the base of the third cartilage; but four abduct it, obviously the ones that join the third to the second [ $\mathrm{mm}$. cricoarytenoidei posteriores et laterales].

\section{THE COMMON MUSCLES}

Other muscles, which we call common [extrinsic], are leaders of either motion by which the air passage or the lingula [rima glottidis] is opened and closed. The first two of these, one on each side ( $\mathrm{F}$ in figures 1 and 2 ) [ $\mathrm{mm}$. thyrohyoidei], originate from virtually the entire lower seat of the hyoid bone; they are wide and fleshy, both next to the inner sides, and seem contiguous. Extending downward from here, and departing from the inner walls, each one is implanted into the lower seat [linea obliqua] of the first cartilage on its own side, of the same width as that of their origin. Throughout their entire descent, where they are stretched out along the anterior surface of the first cartilage, these adhere by fibrous connectors alone, in the same way as adjacent muscles are joined together. Further, at the insertions of these muscles, which stand out no less than their fleshy origins, two other muscles [ $\mathrm{mm}$. sternothyroidel] (one of which is $\mathrm{G}$ in figures 1 and 2) practically as wide are implanted in the first cartilage, taking their origin, with fleshy but not wide beginnings, from the inner region of the pectoral bone [manubrium sterni] in the throat. These muscles, extending upwards along the anterior seat of the rough artery and gradually rendered wider, are inserted in that seat [linea obliqua] of the first cartilage which we mentioned. The fifth and sixth of the common muscles of the larynx are transverse $[m$. constrictor pharyngis inferior] (I in figures 1, 2, 3, 4, 5), and there is one of these on each side embracing the gullet, for they take their beginning from the back part of the gullet where it faces the vertebrae of the neck, following the longitude of the gullet; they are so mutually continuous that you would almost say the origin of either is one and the same [raphe pharyngis]. Large and fleshy at their origin, they extend transversely forward and are longitudinally implanted in the sides of the first cartilage. Throughout their bulk, where they come into contact with the gullet, these muscles share thoroughly in their origin and extent. These muscles [ $m$. constrictor pharyngis inferior] which we last reviewed contract the sides of the first cartilage to the rear, so pressing it against the second cartilage that they constrict the larynx also, or the lingula [glottis]. On the other hand, the muscles which proceed from the hyoid bone [ $m$. constrictor pharyngis medius] pull the first cartilage somewhat upward from the posterior [parts] and dilate 


\section{H. Garrison and M. H. Hast}

the larynx. The muscles from the pectoral bone inserted in the first cartilage [ $\mathrm{mm}$. sternothyroidei] achieve the opposite function; for these lower muscles contract the seats of the first cartilage and turn them downward, at the same time somewhat contracting and tightening the rough artery, so that when a person utters a sound nothing will be repeated or extended excessively.

\section{TWO MUSCLES OF THE OPERCULUM OF THE LARYNX}

Besides these six, I have noticed two others [ligamentum hypoepiglotticum] ${ }^{60}(\mathrm{~K}$ in figures $2,3,4)$, rather smooth and rounded and pulled up out of the middle interior seat of the hyoid bone and inserted one on each side in the root of that body [epiglottis] ( $\mathrm{L}$ in figures $2,3,4,5)$ which is considered the operculum of the larynx. These present themselves rather clearly to the eye (if only one knows the method of demonstrating them); but I believe they were unknown to Galen, since he has made mention of them in none of his works that are today extant; for one would assuredly not think they should be omitted from the number of the common muscles of the larynx. For although Galen said these were eight and at the same time described only six, yet he later added to his account that all eight were joined to the first cartilage. Further, to these two was credited the function of lifting the operculum of the larynx again after it has been closed for food or drink, for when their origins are pulled towards the hyoid bone, the operculum is seen to be elevated. Yet I have observed no muscles that perform the opposite function to these two; this is not surprising, since food and drink easily compress the turned-up, raised operculum of the larynx by their own weight, and weighed down also by its own mass, the operculum is quickly placed against the larynx. These are not, however, the only muscles deprived of opposites; there are also those by whose good offices we draw the straight intestine and the testes $^{61}$ are said to be drawn upward. For the bodies which by their own nature better tend downward and do not perform their peculiar motion in a pull which is downward, are least in need of particular muscles for this action.

\section{LIGAMENTS OF THE LARYNX}

The larynx has absolutely no rare or peculiar ligament beyond the membraneous ligaments encircling the joints in a series of rings; then the lingula [vocal folds], an account of which was given in the preceding Book, is located in its mid part; it is shaped by the articulation of the cartilages, particularly by the parts of the third cartilage which face the first cartilage with sharp processes (vocal); and there being next in order an attaching ligament [ligamentum vocale] and a fatty membrane [tunica mucosa] enclosing the entire larynx [cavitas laryngis], I would prefer you learn its nature and the technique of construction with your own hands by dissection, as I shall now set forth. ${ }^{62}$

\footnotetext{
${ }^{60}$ See note 45 above.

61 A testis can be elevated by contraction of the $m$. cremaster.

62 The 1555 edition omits all but the first clause of this section, concluding "we therefore do not describe such a thing at all. And if the larynx perhaps adopts anything proper to itself on account of the membrane with which it is said to be covered or bound, that is referred to the account of the lingula."
} 


\section{Andreas Vesalius on the larynx}

\section{BOOK II}

\section{CHAPTER 22}

\section{DISSECTION $^{63}$ OF THE MUSCLES OF THE LARYNX}

You will first experience the construction of the larynx in a cow or a calf, then in a human. From whichever larynx, you will supply to your work cleaned cartilages to serve (as it were) in place of bones (which should constantly be present in the dissection of muscles); then, after the muscles proper to the hyoid bone have been dissected, ${ }^{64}$ two muscles [mm. thyrohyoidei] will immediately come to your attention proceeding from the hyoid bone to the first [thyroid] cartilage; freeing their beginnings from the bone with a small knife, follow them to their insertion [linea obliqua] by paring the muscles little by little from the cartilage. Then by the same method you will separate the muscles [mm. sternothyroidei] leading from the pectoral bone [manubrium sterni] to the first cartilage, taking them first from the bone and then pulling them gently from the rough artery [trachea] and tracing them to the first cartilage, where they are inserted. When you have inspected these four closely, make a section through the covering of the palate and the inmost parts of the fauces, and extract the larynx with the gullet [oesophagus] from the jaws in exactly the way butchers are accustomed to remove the larynges of cattle. Then when you have next freed the larynx with a portion of the rough artery and the gullet and removed it altogether from the animal, and after the tongue has been cut away you will present the entire larynx to your companion and fellow student of anatomy to hold. Such a companion in my painstaking study of the construction of the larynx was a young man of outstanding talent, Antonius Succha, the rare and great hope of our common city Brussels, and indeed of all Belgium, on account of his singular knowledge of medicine and mathematics. ${ }^{65}$ And so when the larynx has been prepared by this method, next inspect the muscles [ $m$. constrictor pharyngis inferior, pars thyropharyngea] extending out of the posterior part of the gullet to the sides of the first cartilage. To facilitate this, divide them by a long section where the heads come together [raphe pharyngis], take the head of each with a small hook or your fingertips, and carefully separate the whole from the gullet as far as the sides of the first cartilage. It will be possible to learn the action of just six of these common muscles of the larynx, provided only you pull their heads on each side towards their own origins; this done, you will then and there free all of them from the first cartilage and you will concentrate your dissection on the two muscles [ligamentum thyroepiglotticum] which it is said are implanted at the root [petiolus epiglottidis] of the operculum of the larynx.

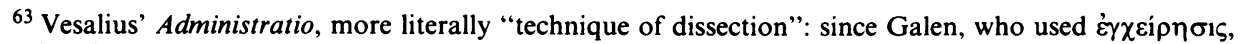
"undertaking, taking in hand, procedure", for dissection, the process was outlined as a step-by-step method.

64 The 1555 edition omits the preceding portion of this sentence, substituting "When the muscles particular to the hyoid bone have been dissected in order, ..."

${ }^{65}$ This sentence was deleted from the 1555 edition, and the preceding sentence condensed as follows: "Then when you have next freed the larynx with a portion of the rough artery and the gullet, you will hand the resected larynx to your partner to hold."
} 


\section{H. Garrison and M. H. Hast}

THE TWO MUSCLES OF THE OPERCULUM OF THE LARYNX

With a circular ${ }^{66}$ incision, cut the covering of the tongue which is common to the inner covering [tunica mucosa] of the palate, larynx, gullet, and finally the operculum itself, toward the root of the operculum, then take hold of it with a hook and strip it off like a skin. Soon the ends of those muscles ${ }^{67}$ will be clearly visible, which afterward you will trace to the hyoid bone by gently separating them from the fat lying nearest them and cut them away from the bone. To learn their function, depress the operculum of the larynx with your finger and when their heads are drawn toward the hyoid bone you will see the operculum being turned up, bent forward, and lifted. ${ }^{68}$ Now also you will remove these muscles [sic] as well as the gullet, and if you like, the operculum itself entirely from the larynx, so that the three cartilages of the larynx are left alone with the twelve muscles belonging to it. When, however, you cut away the remaining part of the rough artery [trachea] from the second [cricoid] cartilage, inspect the glandules [glandulae laryngeales] which are placed next to the human larynx and (as I shall explain in the Sixth Book) are to some degree fleshy. In cattle, you will find in their place a decidedly fleshy substance located near the sides of the second cartilage, similar to any muscle, which could be judged to be the seventh and eighth of the common muscles of the larynx in cattle, where the human possesses large and conspicuous glandules [glandula thyroidea] instead of this substance or rather instead of muscles, as I just now said.

\section{HOW TO OBSERVE THE CLEFT OR LINGULA OF THE LARYNX}

But it is now time for you to look into the exact form of the lingula or cleft [rima glottidis]. You will see that the larynx is broad in its higher and lower part, but in its middle it has an elongated cleft fashioned from that substance which we have stated. In order to distend and open this immediately with your own hands before looking at a section of the muscles, grasp the sides of the larynx with the thumb and middle finger of the right hand, meantime inserting the index finger into the interior space of the third cartilage; then put the thumb and index finger of the left hand into the lower orifice of the larynx and with those two fingers of the left hand try to pull the second cartilage away from the first and with the index finger of the right turn the third cartilage outwards. By this method you will see very clearly how the lingula is opened. But if you draw the second towards the first with your left hand, and push the third cartilage toward the inside with your right thumb and index finger, and in turn make its two parts close up, you will observe the lingula [rima glottidis] being closed exactly. ${ }^{69}$ Now I write these things at somewhat greater length, so that Galen may finally be understood, and those who today profess themselves followers of Galen may not hereafter contend that the operculum of the larynx is the principal organ of speech, or think that the glottis or lingula is the same body as the epiglottis or what is

\footnotetext{
66 The 1555 edition substitutes lunari "moon-shaped" for orbiculari to describe this incision.

${ }^{67}$ A ligament, see note 45 above.

68 Upon their release, after being stretched, the elastic glosso-epiglottic, hyoepiglottic, and thyroepiglottic ligaments shorten to their original lengths.

69 Manipulation of the laryngeal cartilages to demonstrate abduction or adduction of the vocal folds, resulting in dilation or constriction of the rima glottidis through which air is exhaled.
} 


\section{Andreas Vesalius on the larynx}

called by us the operculum of the larynx, clearly failing to recognize that the lingula [plica vocalis] is in the middle of the larynx, and is as similar as can be to the reeds by which flutes are played.

\section{DISSECTION OF PARTICULAR [INTRINSIC] MUSCLES 1, 2, 3, AND 4}

After you have opened and closed the lingula [rima glottidis] with your hands, as has been seen, dissect the particular muscles of the larynx, beginning with the four [mm. cricothyroidei] that bind the second cartilage to the first. With a light transverse cut, free the outer muscle [ $m$. cricothyroideus, pars recta] from the scutiform [thyroid] cartilage, being careful not to damage the inner muscle [ $m$. cricothyroideus, pars obliqua] at the same time; after this is removed, shave off the inner muscle in the same manner from the second [cricoid] cartilage, paying attention to that intersection of fibres of which I have spoken. Do not just investigate whether there are exactly one or two fibres, but also, while you are freeing the gullet from the larynx, judge carefully whether you are going to find those muscles which I was saying are sometimes observed, which are inserted from the ridge of the second cartilage into the lower processes of the first cartilage. ${ }^{70}$ And so when the four muscles joining the second cartilage to the first have been cut away from the larynx, on the other side of the larynx free the lower process [cornu inferius] of the first [thyroid] cartilage from the second and by this method bend the first forward away from the second to examine the two muscles [mm. thyroarytenoidei] binding the third cartilage to the first.

\section{PARTICULAR [INTRINSIC] MUSCLES 5-8, 9 AND 10}

When you have examined these as well as possible, it will be a simple matter to remove the first cartilage from the remaining two with a small but sharp knife, or, if you wish, keep the third [cartilago arytenoidea] attached to the two muscles [ $\mathrm{mm}$. thyroarytenoidei] binding it to the first, and later go on to the four muscles [ $\mathrm{mm}$. cricoarytenoidei laterales et posteriores] connecting the third cartilage to the second. It will be possible to free these muscles from their origins, which start out from the second cartilage, and trace them to the third cartilage, into which they are inserted.

\section{PARTICULAR [INTRINSIC] MUSCLES 11 AND 12}

Finally, take away the muscles $[m \text {. arytenoideus transversus }]^{71}$ which are in the base of the third cartilage, similarly also freeing their beginnings first, and scraping them away as far as their end where they touch each other, for by this kind of procedure it will always be possible without impediment to learn the function of the muscles while their beginnings are drawn toward the point from which they take their origin. ${ }^{72}$ After the muscles are removed, separate the cartilages in turn, and you cannot but have the substance of the lingula [plica vocalis] carefully disposed in the clearest view, and to an extent its nature, use, and form by means of procedures that you have now performed with your own hands.

\footnotetext{
${ }^{70}$ See note 45 above.

${ }^{71}$ See note 47 above on the transverse arytenoid.

72 The 1555 edition omits the last portion of this sentence following the comma.
} 


\section{ON THE VASCULAR SYSTEM OF THE LARYNX \\ BOOK III \\ CHAPTER 7 \\ (excerpt from page 285)}

The portion [vena jugularis interna] entering the inner part of the face [vena facialis], in its first divisions bypasses the glandules which are the inferior ones in the pharynx [nodi lymphatici cervicales anteriores] and which we shall enumerate in the Sixth Book as the third type of glandules. From these glandules, which are here responsible for distributions of vessels, little branches are distributed from the interior portion of the external [sic] jugular and soon are derived noteworthy twigs into the larynx ( $v$. laryngea superior] and the glandules [nodi lymphatici paratracheales] immediately adjacent to it, and the muscles of the hyoid bone [ $v$. jugularis anterior], and of the tongue [ $v$. lingualis], and in general to all portions of the pharynx [plexus pharyngeus]. The most conspicuous of these twigs runs under the tongue [v. submentalis] along its longitude, being divided into numerous branches running forward in a wandering series.

\section{BOOK III \\ CHAPTER 12 \\ (excerpt from page 301)}

When the sleep artery [arteria carotis communis] of the left side (in the same way as the right) reaches the pharynx, it is split into two branches, the larger and inner [arteria carotis externa] of which enters the pharynx, and soon forming branches of the larynx [a. laryngis superior] and tongue [a. lingualis], proceeds to the base of the skull: but prior to entering the skull, it is drawn into two unequal branches... .

\section{ON THE INNERVATION OF THE LARYNX \\ BOOK IV \\ CHAPTER 9 \\ (excerpt from page 327)}

\section{The Sixth Pair of Cerebral Nerves}

Of the remaining pairs that take their beginning from the cavity of the skull, no pair puts out a shoot so sparse of branches, or is introduced into so many and various places, as the sixth couple ${ }^{73}$ of cerebral nerves, which takes its beginning a little lower

\footnotetext{
${ }^{73}$ Following Galen, Vesalius' “sixth pair” of cranial nerves includes nervus glossopharyngeus, nervus vagus, and nervus accessorius.
} 
Andreas Vesalius on the larynx

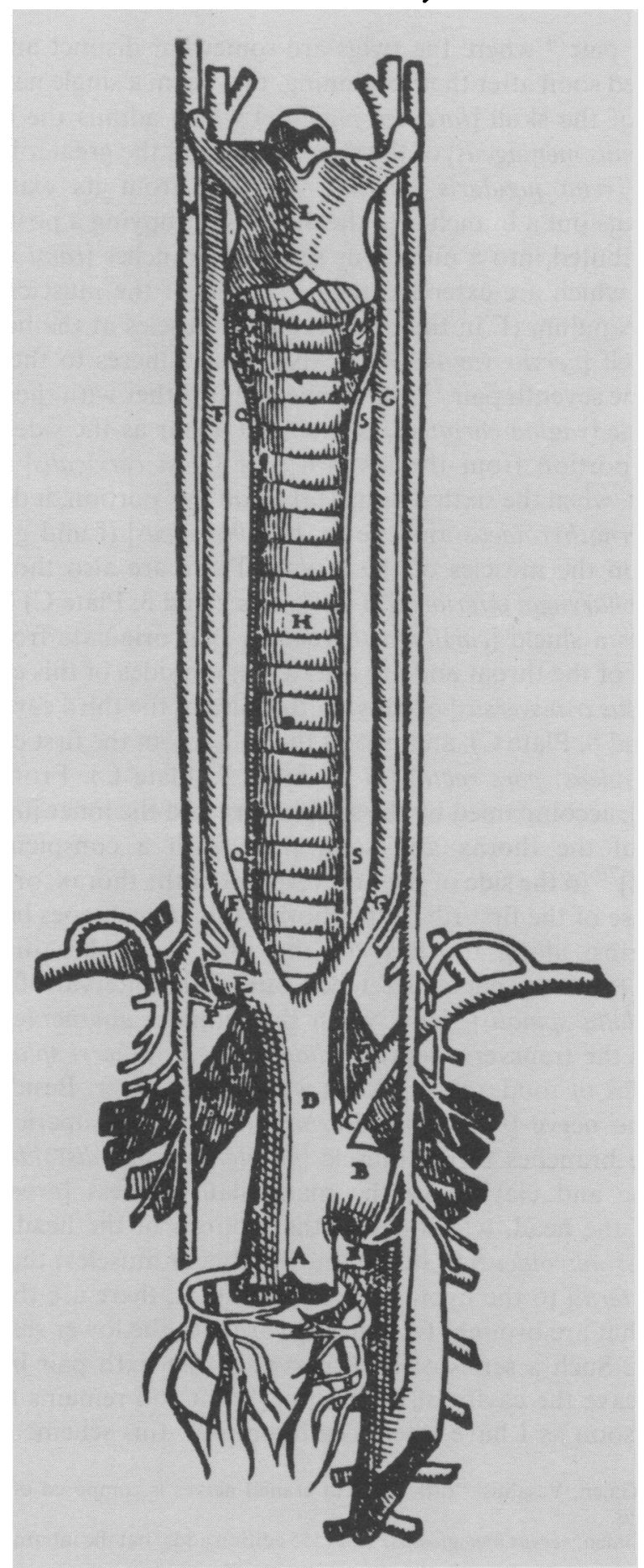

Plate $E$ : The course of the recurrent laryngeal nerve. 


\section{H. Garrison and M. H. Hast}

than the fifth pair ${ }^{74}$ where the twigs are somewhat distinct and separate from one another. Joined soon after their beginning, they form a single nerve that exits through the foramen of the skull [foramen jugulare] which admits the lesser branch [arteria occipitalis, ramus meningeus] of the sleep artery and the greater branch of the internal jugular vein [vena jugularis interna]. Not far from its exit, this nerve [nervus accessorius] puts out a branch into the muscles occupying a posterior seat in the neck which is distributed into a numerous series of branches [rami musculares], the most important of which are extended to the second of the muscles [musculus trapezius] moving the scapulum ( $\Gamma$ in the ninth table of muscles at the beginning of Book II). The trunk itself [nervus vagus] of the sixth pair adheres to the sleep artery (arteria carotis] and the seventh pair, ${ }^{75}$ and connected together with these by the intervention of a membrane [vagina carotica], is extended as far as the sides of the larynx, there taking on a portion from the seventh pair [ansa cervicalis] and increasing itself thereby. Then, when the sixth pair has taken on this portion, it displays little branches (to the $m$. sternothyroideus and the $m$. thyrohyoideus] (f and $\mathrm{g}$ in figure 2 , Plate $\mathrm{C}$ ) transversely on the muscles of the larynx. There are also those two muscles $[\mathrm{mm}$. constrictores pharyngei inferiores] (I in figures 2 and 3, Plate $\mathrm{C}$ ) just near the cartilage that resembles a shield [cartilago thyroidea], that originate from the gullet and the posterior seat of the throat and are inserted in the sides of this cartilage; then the two [ $m$. arytenoideus transversus] occupying the base of the third cartilage [c. cricoidea] ( $\mathrm{V}$ in figures 7 and 8, Plate $\mathrm{C}$ ), and two of those that join the first cartilage to the second [m. cricothyroideus, pars recta] ( $\mathrm{N}$ in figure 4, Plate $\mathrm{C}$ ). From here the sixth pair [nervus vagus], accompanied by the sleep artery and the inner jugular, descends to the higher seat of the thorax and soon puts forth a conspicuous branch [truncus sympatheticus $]^{76}$ to the side of the first vertebra of the thorax, or rather to the anterior seat of the base of the first rib of the thorax; this branch goes beneath the membrane joining the ribs, along the base of the ribs, and takes in certain twigs [nervi intercostales] from the nerves stretched out in the interval of ribs from the dorsal medulla [medulla spinalis]. Now when this branch, augmented by this manner of twigs, crosses the transverse septum [diaphragma], it [nervi splanchnici] is distributed into the organs of food and drink, as we shall say later. Besides this branch of the sixth pair, the nerve [nervus accessorius] next to the superior seat of the thorax presents little branches to the muscle [m. sternocleidomastoideus] leading from the pectoral bone and clavicle to the mammilate process [processus mastoideus, os temporale] of the head, which assists the motions of the head. Next, it goes to the muscle [ $m$. sternohyoideus] ( $\mathrm{S}$ in the fourth table of muscles) that runs from the chest [manubrium sterni] to the hyoid bone. In addition, there are those (nervi laryngeales recurrentes] that are brought from here [thorax] to the lower seat of the first cartilage of the larynx. Such a series of both nerves of the sixth pair [nervous vagus] is seen before they leave the cavity of the thorax. What still remains to be narrated will be described as soon as I have inserted a figure into this scheme.

\footnotetext{
${ }^{74}$ Following Galen, Vesalius' "fifth pair" of cranial nerves is composed of nervus facialis and nervus vestibulocochlearis.

${ }^{75}$ Following Galen, nervus hypoglossus. The 1555 edition adds that the internal jugular vein is included in this bundle.

${ }^{76}$ The sympathetic trunk is part of Vesalius" "sixth pair" of cranial nerves.
} 


\section{Andreas Vesalius on the larynx}

THE RIGHT RECURRENT NERVE

And so when the right nerve of the sixth pair [nervus vagus] has entered the cavity of the thorax, and moves among the arteries and veins in the throat, it puts out from its interior side two or three small branches which soon move on upwards in turn, constituting the returning nerve [nervus laryngealis recurrens] of the right side. ${ }^{77}$ For these small branches join together at the artery [arteria subclavia], which extends to the right armpit [regio axillaris], as if bent back on a pulley, and they make up a single nerve running upward next to the right side of the rough artery [trachea]. For when, for the first time, a single nerve is put together out of those little branches ${ }^{78}$ (in whose place sometimes a single one is seen) and goes toward the right side of the rough artery, and by the intervention of a membrane is attached to it, it runs to the right side of the larynx, pressing on the glandule [glandula thyroidea] ( $\mathrm{M}$ in the diagram), which resembles other glandules neither in colour nor in substance, and is recognized at the root of the larynx here on the right side (as is another on the left). Just at that point where the nerve comes in contact with the larynx, it is divided into several twigs leading off into the muscles of its own side. I will add an explanation of what those muscles are after I have traced the left recurrent nerve leading to the left side of the larynx.

\section{THE LEFT RECURRENT NERVE}

The left nerve of the sixth pair [ $n$. vagus], now having entered the cavity of the thorax, is unable to extend the branches of the artery propagated into the left hand so that they are bent back upwards because the artery [a. subclavia] runs to the armpit obliquely upwards, not transversely in the manner of the right artery. For the turning back of any nerve is in no way as safely accomplished on the oblique as it is on the transverse; indeed, if it is turned back toward the oblique rod [a. subclavia sinister] it gradually climbs upward, the turning point never keeping the same place; and the more the left nerve descends all the time to the base of the heart, the more it touches the trunk of the great artery [aorta] outside the envelope of the heart, which [pars descendens aortae] is extended downward toward the spine. Now here three or even fewer branches $(R \text { in the diagram, Plate } D)^{79}$ are soon led out of the nerve [vagus], which after bending backward at the trunk of the artery [arcus aortae] where it is deflected toward the spine, are in turn united and make up the left recurrent nerve. This nerve, proceeding upwards, is applied by means of a membrane to the left side of the rough artery; and as soon as it touches the larynx it is diverted into branches no less than the right nerve; all of which come to an end with their heads leading downwards into the muscles [ $\mathrm{mm}$. laryngis] of their own side. There are those, moreover, if you include the muscles of each side, four [ $\mathrm{mm}$. cricoarytenoidei posteriores et laterales], binding the third to the second cartilage, by virtue of which the third cartilage is drawn backward and to the sides, and the lingula [rima glottidis] of the larynx is opened. Besides these [there are] two [ $\mathrm{mm}$. thyroarytenoidei] joining the third cartilage to the first, which close the fissure of the larynx or lingula, and

\footnotetext{
${ }^{77}$ Only one branch constitutes the right or left recurrent laryngeal nerve; the other branches of the vagus nerve, at this level, are cervical and thoracic cardiac branches and pulmonary plexi.

78 See note 77 above.

${ }^{79}$ See note 77 above.
} 


\section{H. Garrison and M. H. Hast}

virtually alone resist expiration, when as we exhale we hold the breath back by force, and at the same time as much as we are able, we labour at expiration with our other muscles. To these, besides several others, run the muscles of the tongue $[\mathrm{m}$. genioglossus and $m$. hyoglossus], originating from the middle of the bone resembling $v$ [hyoid] so that they move the tongue.

\section{WHY REVERSING NERVES ARE MADE}

For when the present muscles acquire their heads in a lower position and have been destined to pull a body to be moved necessarily downward, we believe it is also inevitable that the animal's breath be drawn by them to some degree upwards from the lower parts. With how much industry the infinite Maker of our body had laboured to bring this about in the convolution of these nerves, ${ }^{80}$ you may discern both from the dissection itself, and from this concise narration of the distribution of the nerves, and from that diagram which we displayed beforehand. Likewise I urge that you go to Galen, who deservedly prides himself on having first discovered these bendings of the nerves. In the seventh Book of De usu partium ${ }^{81}$ he employs true hymns to God and asks for a more heedful mind than if you attended the Eleusinian, Samothracian, or any other divine celebration with sympathetic ears and listened attentively to what was said and done by the priests. For Galen justly believes that the celebration therewith given forth is in no portion inferior to these, and displays no less the unbelievable wisdom, foresight, and virtue of God, the maker of all.

\section{BOOK IV CHAPTER 10}

\section{On the Seventh Pair of [Cerebral] Nerves}

The seventh [nervus hypoglossus] and final pair of the nerves of the cerebrum, as it is harder than the other pairs, so also it originates from a harder beginning; for it starts out from the twigs that stand somewhat apart from each other, from the dorsal medulla [medulla oblongata] where it has just left the skull. From here is it moderately stretched in an anterior direction, and, its twigs coming together into one, it passes through a foramen [canalis hypoglossi] particularly carved for it. As soon as this seventh pair has exited the skull, it adheres to the sixth pair, and distributes some branches to the muscles that originate from the processes which imitate a stylus [processus styloideus]. Among these muscles is the second of the third pair of muscles peculiar to the hyoid bone [ $m$. stylohyoideus], and the muscle that draws the lower maxilla downward [ $\mathrm{m}$. digastricus], and another belonging to the tongue $[\mathrm{m}$. styloglossus]. The seventh pair, descending from here as far as the base of the tongue, is

\footnotetext{
80 The 1555 edition adds that these are called $\pi \alpha \lambda 1 v \delta \rho \circ \mu \hat{\omega} v \tau \varepsilon \varsigma$ (i.e., reversing, recurrent) by the Greeks; see for example Galen, De locis affectis 8.267.19, Nemesius Emesenus (4th century AD) De natura hominis 14.21, Paulus Aegineta (7th century AD) Epitomae medicae 6.35.2.7, Theophilus Protosparathius (7th century AD) De corporis humani fabrica 3.16. For Galen's description of the recurrent laryngeal nerve, see De usu partium 3.578.17, May, p. 368.

${ }^{81}$ De usu partium 3.576.5, May, p. 367.
} 
divided into several branches [ $n$. hypoglossus, rami linguales; ramus thyrohyoideus; $n$. laryngealis superior], which are enfolded into the muscles of the tongue, the muscles of the hyoid bone, and all the muscles of the larynx not enumerated above [ $\mathrm{m}$. cricothyroideus]; these nerves are responsible for their movement. Besides these branches, the seventh pair presents no small portion of itself to the sixth pair of cerebral nerves there at the base of the tongue, augmenting the sixth pair by that portion.

\title{
ON THE GENERATION OF THE VOICE
}

\author{
BOOK VI \\ CHAPTER 4 \\ ON THe Rough Artery \\ (excerpt beginning page 577)
}

\section{WHY CARTILAGE ENTERS INTO THE MAKEUP OF THE ROUGH ARTERY [TRACHEA]}

Yet it abounded also with cartilages so that it could become the organ not just of respiration, but also of speech. For just as it was suitable for the rough artery to be constructed out of membrane like the smooth arteries for the sake of respiration, so also to produce vocalization it needed to be fashioned quite broad, rigid, and hard in the manner of pan-pipes, reed-pipes, and trumpets. There should be a certain symmetry in order that a voice be made, and there should also be the strength of the bronze itself and of the material struck by it. Cartilage is certainly a substance of this kind, from which it was appropriate that the entire [rough] artery be made like a flute, without ligaments and membranes. But since without inhaling and exhaling a voice cannot be made in any way, and that necessarily requires compression and distension, we will justly praise the intelligence of the greatest Maker of things, who made the rough artery the convenient organ of respiration and the voice at the same time. And he showed such skill in the construction of the larynx, that it is able to be closed now more, now less, and by our own decision we are able to hold back breath itself often for great uses, and make our voice now heavy, now light according to how we tighten or relax that fissure (which is surely the chief instrument of the voice).

\section{USE OF THE FISSURE [PLICA VOCALIS] OF THE LARYNX}

Now it is this which we have said is like pipers' joined pieces of reed: and it also resembles that fissure which is in the pipes we hold in our lips. For it corresponds in use, if not in form, to the openings of horns and tubas which we place against our mouth when we blow into them. Then again this crack is comparable to the openings in the reeds of organs and to the opening of those reeds which we blow into transversely. Yet the larynx far surpasses the workmanship of all pipes, and it far surpasses the artifice of all orifices or fissures of the type in which sound is produced. ${ }^{82}$ It is so fashioned that we are able to relax it now more now less, and are

\footnotetext{
${ }^{82}$ The last clause is added in the 1555 edition. "I have demonstrated in my book on the production of the voice that this larynx is the first and most important instrument of the voice."-Galen, De usu partium 3.611.14 and 4.278.9, May, pp. 339-40.
} 


\section{H. Garrison and M. H. Hast}

able to produce various voices, not just a single one (like the instruments of artisans). And, finally, such strength is placed in the thorax that at will we can emit now much, now little air just for breathing, or at the same time whatever air suffices for a vocal utterance that we wish to make during expiration.

\section{GENERATION OF THE VOICE}

You will be aware how essential it was that the second [cricoid] cartilage of the larynx form a perfect circle, and that the rough artery cannot be compressed here at the root of the larynx, if you have diligently learned that the voice is generated out of air driven from a wide passage into a narrow one and from here back into a wide one, and at the same time if you have scrutinized the uvula-the plectrum of the voice-and the palate constructed like a large, round space, and the cavity above it appearing in the sinuses of the nostrils [meati nasi], and the caverns [sinus maxillares] of the fourth bone on either side of the upper maxilla, and likewise the teeth, the tongue, and the lips, and finally the musical instruments of artisans, and diligently compared the function of their components with these works of Nature.

\section{USE OF THE LARYNGEAL OPERCULUM [EPIGLOTTIS]}

It does not seem appropriate to enter here into a dispute about names by quarrelling about the name of this fissure [plica vocalis] and the operculum of the larynx, which many falsely count as the proper and principal instrument of the voice, although this operculum provides nothing to the voice except perhaps some modulation of it, and serves only (as we also mentioned in the first Book) to prohibit the fall of food and drink into the larynx in the process of swallowing. For besides having it clearly evident to our senses from true dissection that this has nothing to do with the voice, this fact should have been known to others through reason: for no muscle has ever been observed by others by which this operculum would be activated, nor indeed is it moved by any [except] those which we mentioned are brought to it from the hyoid bone, while in the meantime the remaining muscles of the larynx all serve the single function of widening and narrowing that fissure. In addition, you will recognize that the entire structure of the laryngeal cartilages is built because of it, if you have been fired by even the slightest spark of enthusiasm to learn the works of Nature and do not reject knowledge of them, like the most unworthy man ever created by Nature. For when you take in hand the larynx even of some dumb animal, you will take the greatest pleasure in admiring how the industry of artisans in preparing musical instruments follows the works of Nature. ${ }^{83}$

\footnotetext{
${ }^{83}$ For the 1555 edition, Vesalius rewrote the end of this section as follows: "In addition, you will recognize, not without the greatest pleasure, that the entire structure of the laryngeal cartilages is built because of it, at least if you burn with some zeal to learn the works of nature, or have taken the larynx of some animal in your hands, and expended energy on the musical instruments of craftsmen, which closely imitate the works of nature."
} 